\title{
Assessing the institutional foundations of adaptive water governance in South India
}

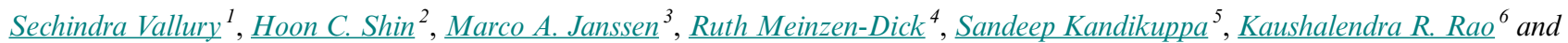 \\ Rahul Chaturvedi ${ }^{7}$
}

\begin{abstract}
Institutional structures can fundamentally shape opportunities for adaptive governance of water resources at multiple ecological and societal scales. The properties of adaptive governance have been widely examined in the literature. However, there has been limited focus on how institutions can promote or hinder the emergence of adaptive governance. Elinor Ostrom's institutional theory stresses the importance of formal and informal norms and rules in effective governance of natural resources. Specifically, Ostrom's "design principles" (DPs) are considered important because they increase the capacity for adaptive decision making and facilitate the emergence of self-organization at smaller scales. Self-organizing agents can frequently modify rules-in-use, procedures, and technical methods to tackle changing ecological conditions and address significant management issues left by more traditional governments. In this study, we examine institutional arrangements for successful water governance by analyzing (1) the co-occurrence of DPs in irrigation systems, and (2) the combination(s) of DPs leading to social and ecological success. We collaborated with a local non-profit organization to review institutional records and conduct interviews in 50 irrigation communities in Andhra Pradesh and Karnataka in South India. Using qualitative comparative analysis, we found that the effectiveness of design principles is contingent on biophysical properties, such as the size of the watershed being governed, and attributes of the community, such as population size. We also discuss the methodological and data-related challenges involved in collecting primary data for conducting a context-specific institutional analysis. Our study offers a much-needed example of empirical research that investigates the role of operational level rules in adaptive water governance.
\end{abstract}

Key Words: adaptive water governance; design principles; institutions; irrigation systems; qualitative comparative analysis

\section{INTRODUCTION}

Small-scale irrigation systems contribute to nearly $40 \%$ of the world's food production and play a critical role in sustaining global food security (Bruinsma 2017). The availability of water in these systems is threatened by increased challenges resulting from environmental stressors like climate change. Much attention has been paid in the literature on the role of environmental governance to address water scarcity issues (e.g., Knieper et al. 2010, Groenfeldt and Schmidt 2013, Hill 2013, Hurlbert and Diaz 2013, Pahl-Wostl 2019). Current environmental governance structures are often driven by policies that fail to adapt to changing social-ecological conditions (e.g., Ruhl 2010, Cosens et al. 2014) and rigid institutions (Folke et al. 2007, Arnold and Gunderson 2013). These limitations can threaten human welfare (Dietz et al. 2009), especially as water scarcity issues expand over multiple jurisdictional, cultural, and economic scales. Therefore, new approaches are necessary that incorporate a broader set of institutions to become more flexible and adaptive to climate uncertainty (Folke et al. 2005, Chaffin and Gunderson 2016). Over the past decade, adaptive governance is increasingly called upon by scholars to overcome the limitations of current approaches and incorporate elements of flexibility and collective cooperation (Dietz et al. 2003, Chaffin et al. 2014).

Adaptive governance is generally understood as an emergent phenomenon of a system with the necessary flexibility and capacities to adapt to stressors that are inherent to socialecological systems (SES; Gunderson et al. 1995, Folke et al. 2005, Pahl-Wostl et al. 2012, Chaffin et al. 2014). Such adaptation often occurs at multiple centers of authority (or environmental stakeholders) in SESs (Ostrom 1990, Chaffin and Gunderson 2016). Improving the potential for adaptation and adaptive governance depends heavily on legal and institutional mechanisms for facilitating coordination and innovation between stakeholders (Dietz et al. 2003, Arnold and Gunderson 2013, Craig and Ruhl 2014). Specifically, governing authorities at differing scales may design institutions that enhance the ability of key environmental stakeholders, such as grassroots organizations and resource users, to make adaptive responses to changing socialecological conditions (Shivakumar 2005, Clarvis et al. 2014, Cosens et al. 2017). Several scholars have suggested theoretical principles for institutional design aimed at enhancing the ability of environmental stakeholders to self-organize and collectively address challenges (Shivakumar 2005, Sarker 2013, Cosens et al. 2017, Craig et al. 2017, DeCaro et al. 2017, Hurlbert and Gupta 2019). However, studies of the fit between institutions and their environment (Folke et al. 2007, Epstein et al. 2015) ask us to empirically investigate how contextual conditions mediate the effectiveness of governance institutions in fostering adaptive governance.

This study explores the question of the interactions between adaptive governance institutions and contextual factors. We examine Elinor Ostrom (1990)'s institutional design principles (DPs) as an example of institutions that facilitate self- and adaptive governance. The advantage of facilitating selfgovernance or self-organizing agents is that resource users can frequently devise rules to address resource-related challenges that are often not addressed by traditional governments (Ostrom 1990, 2005). Ostrom's DPs have been recognized as community-level

${ }^{1}$ W.A. Franke College of Forestry \& Conservation, University of Montana, ${ }^{2}$ Institute of Water Policy, Lee Kuan Yew School of Public Policy, National University of Singapore, ${ }^{3}$ School of Sustainability, Arizona State University, ${ }^{4}$ International Food Policy Research Institute, ${ }^{5}$ Environment Ecology and Energy Program, University of North Carolina, ${ }^{6}$ SELCO Foundation, ${ }^{7}$ Foundation for Ecological Security 
rules that increase the capacity of resource users for adaptive decision making (Ostrom 2014) and facilitate the emergence of adaptive governance (Dietz et al. 2003). On the other hand, contextual factors are generally defined as "dynamic forces constituted in the user groups' social, cultural, economic, political, technological, and institutional environment" (Edwards and Steins 1999:207). Such local contextual factors are typically endogenous forces that may affect access to the resource, infrastructure maintenance, and/or the demand for resources by individuals. In this study, we investigate how institutional DPs and contextual conditions interact to affect the ability to selforganize and collectively address challenges concerning water allocation and infrastructure provision.

To do this, we conduct a comparative analysis of 50 shared irrigation systems in South India. In these systems, shared surface reservoirs contribute to smoothing the availability of water in the face of environmental uncertainty (Mosse 2006, Vallury et al. 2020). The reliance of agricultural productivity on shared infrastructure requires a sufficient level of collective action for both infrastructure maintenance and water allocation under environmental variability. Furthermore, these systems show social and biophysical heterogeneities in terms of the group size and resource areas that affect transaction costs of resource governance (Isaac et al. 1994, Agrawal and Goyal 2001, Carpenter 2007, Poteete and Ostrom 2004, Shin et al. 2020). Hence, such infrastructure-mediated irrigation systems provide an excellent testing ground for exploring how DPs and social-biophysical conditions jointly affect outcomes of adaptive self-governing systems.

In this paper, we also attempt to make methodological progress on examining configurations of variables that co-occur to produce outcomes in social-ecological systems. Extant literature on the theory of SESs governance often takes an "oversimplified variable-to-outcome" approach and ignores the joint effects of interacting variables on outcomes (Villamayor-Tomas et al. 2020). We address this gap by using qualitative comparative analysis (QCA): a systematic way to identify causal factors for outcomes by comparing the outcomes of different combinations of explanatory variables across the sample (Ragin 2008, Rihoux and Ragin 2009, Schneider and Wagemann 2012). Recent metaanalysis studies used QCA to examine the joint effects of institutions, specifically the DPs, on successful self-governance (Baggio et al. 2016, Shin et al. 2020); yet these analyses rely on secondary case data, raising concerns about potential biased selection of individual cases, incomplete information on each case, and subjective interpretation of the intent of the original authors in relation to the information to be coded (Barnett et al. 2016). Hence, a systematic collection of primary data of a large number of cases is desirable for more accurate comparative analysis of multiple self-governance cases (Lam and Ostrom 2010, Whittaker et al. 2021).

An alternative approach, which we explore in this paper, is to develop a protocol that enables practitioners to collect data. A reason for practitioners to participate in such a data collection effort is to enhance their ability to analyze the conditions for success of governance interventions. If successful, this will enable researchers and practitioners to collect data of many more cases in a consistent form and to better understand the ways social and biophysical context impact institutional arrangements that are likely to lead to effective governance. In this paper we present our experience with a unique opportunity to collect primary data of a large number of cases in one geopolitical system, namely villages in Andhra Pradesh and Karnataka, India. We used the code book developed by Ratajczyk et al. (2016), which is a condensed version of the original code book of Ostrom (1990).

\section{METHODS}

\section{Case selection and data collection}

Our study sites are located in the Chittoor and Anantapur districts in the state of Andhra Pradesh, and Chikballapur and Kolar districts in the state of Karnataka in southeast India (Fig. 1). Andhra Pradesh has a net irrigated area of 3.73 million hectares (Directorate of Economics \& Statistics 2018) and the net irrigated area in Karnataka is 2.87 million hectares (WRD 2017). We reviewed institutional records and conducted interviews and focus group discussions in 50 irrigation villages across both states. Table A1.1 lists the 50 villages along with their contextual variables.

Fig. 1. Location of study sites in the Chittoor and Anantapur districts in Andhra Pradesh (dark gray), and Chikballapur and Kolar districts in Karnataka (light gray) in South India.

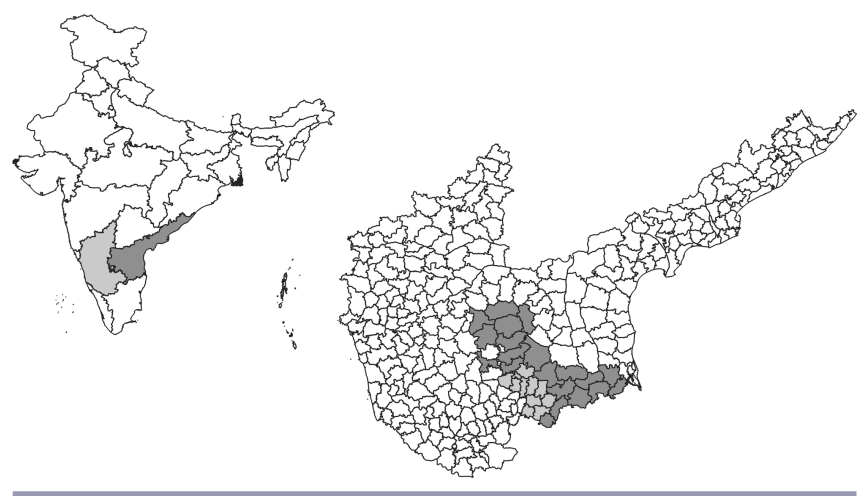

We collaborated with a non-profit organization called Foundation for Ecological Security (FES) for data collection. FES has a long history of working with local communities to conserve natural resources and sustain livelihoods. The organization plays a key role in assisting local resource management organizations, e.g., water user associations (WUA), to craft rules for managing their irrigation infrastructure and water resources. Therefore, we relied on their expertise to select our sample of 50 villages for piloting this project. These were all predominantly agricultural communities that relied on irrigation infrastructure, such as canals and surface reservoirs, to access shared water resources. Based on Ostrom (2005)'s vertical approach to rules-in-use, our criteria for choosing a village was that they maintained written records of the (1) operational rules for governing shared water resources and irrigation infrastructure (e.g., water allocation, labor provision, farmers' regular meetings); and (2) collective-choice rules that affect operational activities and results (e.g., how to elect a water user association's committee, how to change operational rules). One limitation of our sampling approach is that our study sample is limited to the irrigation communities where FES has an extensive involvement in designing these rules. This may bias our sample in such a way 
that communities that have successfully facilitated selforganization of farmers have a higher sampling probability than unsuccessful communities. We discuss a few ways to address this limitation in the next section.

Ratajczyk et al. (2016)'s codebook is divided into two components. The first 13 questions assess how the institutional arrangements affect socioeconomic and resource-related outcomes in terms of (1) condition of the resource, (2) equity levels amongst resource users with regards to resource access, and (3) collective-choice arrangements. Based on the responses to these outcome questions, the success or failure of a village is calculated. The second section of 27 questions assesses the presence or absence of the design principles in a village. Table 1 shows the 11 design principles, adapted from Cox et al. (2010), and the contextual conditions assessed.

The lead author conducted workshops for the field staff at FES to understand and use the codebook for data collection. The purpose of these workshops was to simulate knowledge transfer from academia to practitioners through informal exchanges and guided discussions. Although our collaborators at FES found these workshops useful, there was still confusion regarding the interpretation of questions in the codebook. Therefore, the lead author led the data collection efforts in seven villages in the summer of 2015 to demonstrate the specific information that was required from the village records to effectively answer the codebook questions. This exercise was critical for ensuring that the FES team was able to replicate the data collection process in the remaining 43 villages during the summer of 2016. Two field staff personnel participated in this study and the data for each case study was collected by one field staff.

The institutional records are typically anywhere between 25 and 40 pages depending on the degree of detail in which rules were recorded. Additionally, we often reviewed records of meeting minutes to collect information regarding our outcome variables (e.g., conflict resolutions, siltation in the reservoirs, rule infringements). The meeting minutes were typically around 100 pages depending on the detail. On average, it took about 3-4 hours to review the institutional records. Another key component of our data collection was validating information in the village records through in-depth qualitative interviews and focus group discussions in each village. The interviews were conducted with all the committee members of WUAs, typically $6-8$ people, in a village. For focus group discussions, we interacted with 10-15 farmers who were not part of the village's WUAs committee. These discussions were conducted in two focus groups, one for men and another for women, and were moderated by the field staff from FES. The interviews and focus group discussions helped correct inaccuracies from the village records and provided information about the general awareness of villagers regarding the rules being implemented for water governance in their village.

\section{Analytical approach: fuzzy-set qualitative comparative analysis (fsQCA)}

Our objective was to understand which combinations of the conditions are likely to lead to the outcome. Given the intermediate sample size $(\mathrm{N}=50)$ and our objective of identifying multiple paths to the outcome, fuzzy-set qualitative analysis (fsQCA) is well suited to addressing the issue of multi-causality, i.e., there may be multiple causal conditions that lead to the same outcome. fsQCA is a set-theoretic method aimed at exploring causal relationships between conditions (similar to independent variables) and an outcome (similar to dependent variable; Ragin 2008, Jordan et al. 2011). Differing from the linear causation, fsQCA uses Boolean algebra to capture causal complexity characterized as three logical features (Grofman and Schneider 2009, Jordan et al. 2011, Schneider and Wagemann 2012, Fiss et al. 2013): (1) conjunctural causation: when an outcome is caused by a single condition or a combination of conditions; (2) equifinal causation: multiple combinations of conditions may generate the same outcome; and (3) asymmetric causation: if the presence of a condition is the cause of an outcome, then non-occurrence of the outcome is not necessarily caused by absence of the condition and may constitute a different explanation. The conjunctural causation is represented by logical AND operator (Boolean multiplication "*"), the equifinal causation by logical OR (Boolean addition "+"), and the asymmetric causation by logical NOT operator (Boolean negation " $"$ ").

The fsQCA approach involves selecting relevant "conditions" and an outcome of interest. In our study, we chose 11 institutional conditions (Ostrom's design principles) and two contextual conditions (group size and resource area per household). The outcome of interest in our analysis is the overall success in a case. fsQCA then compiles the data on the conditions and outcome into a raw data table and assesses the degree to which a case has "membership" in the sets of specific conditions or combinations of these conditions, and the outcome set (Ragin 2008). Using a standard software tool (fsQCA 3.0) developed by Ragin and Davey (2016), our fsQCA of the 50 villages reports logically minimal combinations of conditions that are sufficient for successful self-governance (Rihoux and De Meur 2009). These simplified combinations are called solution terms. By comparing the solution terms, researchers can establish the conditions of necessity and sufficiency (Ragin and Davey 2016). A condition is necessary but not sufficient if it is capable of producing an outcome in combination with other conditions and appears in all solution terms. A condition is sufficient but not necessary if it exists in a certain solution term but is not the only one condition of the solution term. A condition is both necessary and sufficient if it is the one and only condition (i.e., not a combination of conditions) that produces an outcome.

Our analysis proceeded through three stages. First, we ran a model with only institutional conditions (DPs) using fsQCA software. Second, we then included the group size of each village as a contextual condition, and finally we added the resource area per household variable in each village to examine how change in contextual condition affects institutional arrangements.

\section{Outcome and conditions}

Table 2 provides the criteria used to define biophysical outcomes in terms of the state of natural resource and physical infrastructure, and social outcomes in terms of human infrastructure, trust, rule conformance, and equity. We calculated the overall success score of each village as the weighted average of biophysical and social outcomes. Finally, we used the fsQCA software tool to calibrate the success score variable into a continuous scale of $0.0-1.0$ ( 0 being "clearly low success"; 1.0 being "clearly high success"). See Appendix 1 for more details on the outcomes, success score, and the calibration. 
Table 1. Descriptions and measures of the institutional and contextual conditions.

\begin{tabular}{|c|c|}
\hline & Description and measures $($ The presence of Design Principle $=1$; the absence $=0$ ) \\
\hline \multicolumn{2}{|l|}{ 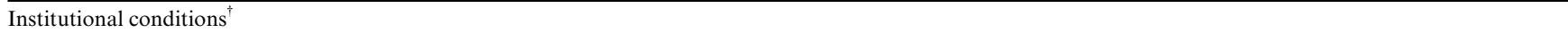 } \\
\hline $\begin{array}{l}\text { Design Principle 1A } \\
\text { (DP1A) }\end{array}$ & $\begin{array}{l}\text { Clearly defined social boundaries: Individuals or households who have rights to withdraw resource units from the common- } \\
\text { pool resource (CPR) must be clearly defined. }\end{array}$ \\
\hline $\begin{array}{l}\text { Design Principle 1B } \\
\text { (DP1B) }\end{array}$ & Clearly defined biophysical boundaries: The boundaries of the CPR must be well defined. \\
\hline $\begin{array}{l}\text { Design Principle } 2 \mathrm{~A} \\
\text { (DP2A) }\end{array}$ & $\begin{array}{l}\text { Congruence between appropriation/provision rules and local conditions: Appropriation rules restricting time, place, } \\
\text { technology, and/or quantity of resource units are related to local conditions. }\end{array}$ \\
\hline $\begin{array}{l}\text { Design Principle 2B } \\
\text { (DP2B) }\end{array}$ & $\begin{array}{l}\text { Proportionality between investment and extraction: The benefits obtained by users from a CPR, as determined by } \\
\text { appropriation rules, are proportional to the amount of inputs required in the form of labor, material, or money, as } \\
\text { determined by provision rules. }\end{array}$ \\
\hline $\begin{array}{l}\text { Design Principle } 3 \\
\text { (DP3) }\end{array}$ & $\begin{array}{l}\text { Collective choice arrangements: Most individuals affected by the operational rules can participate in modifying the } \\
\text { operational rules. }\end{array}$ \\
\hline $\begin{array}{l}\text { Design Principle 4A } \\
\text { (DP4A) }\end{array}$ & $\begin{array}{l}\text { Monitoring CPR conditions and appropriation behavior: Monitors are present and actively audit CPR conditions and } \\
\text { appropriator behavior. }\end{array}$ \\
\hline $\begin{array}{l}\text { Design Principle 4B } \\
\text { (DP4B) }\end{array}$ & Monitoring the monitor: Monitors are accountable to or are the appropriators. \\
\hline $\begin{array}{l}\text { Design Principle } 5 \\
\text { (DP5) }\end{array}$ & $\begin{array}{l}\text { Graduated sanctions: Appropriators who violate operational rules are likely to be assessed graduated sanctions (depending on } \\
\text { the seriousness and context of the offense) by other appropriators, officials accountable to these appropriators, or both. }\end{array}$ \\
\hline $\begin{array}{l}\text { Design Principle } 6 \\
\text { (DP6) }\end{array}$ & $\begin{array}{l}\text { Conflict-resolution mechanisms: Appropriators and their officials have rapid access to low-cost local arenas to resolve } \\
\text { conflicts among appropriators or between appropriators and officials. }\end{array}$ \\
\hline $\begin{array}{l}\text { Design Principle } 7 \\
\text { (DP7) }\end{array}$ & $\begin{array}{l}\text { Minimal recognition of rights to organize: The rights of appropriators to devise their own institutions are not challenged by } \\
\text { external governmental authorities. }\end{array}$ \\
\hline $\begin{array}{l}\text { Design Principle } 8 \\
\text { (DP8) }\end{array}$ & $\begin{array}{l}\text { Nestedness: Appropriation, provision, monitoring, enforcement, conflict resolution, and governance activities are organized } \\
\text { in multiple layers of nested enterprises. }\end{array}$ \\
\hline Contextual conditions & Description and measures \\
\hline $\begin{array}{l}\text { Resource Area per Household } \\
\text { (ARHH) }\end{array}$ & $\begin{array}{l}\text { The total area of a surface reservoir in a village is divided by the group size of the village (hectare/household); continuous } \\
\text { scale of } 0.00467-33.333 \text {. }\end{array}$ \\
\hline $\begin{array}{l}\text { Group size } \\
(\mathrm{HH})\end{array}$ & The number of households in a village; continuous scale of $15-856$. \\
\hline
\end{tabular}

Table 1 shows the 11 institutional conditions associated with Ostrom's design principles (DP1A to DP8), and two contextual conditions hypothesized to affect sustainability of socialecological conditions: group size $(\mathrm{HH})$ and resource area (ARHH; Ostrom 2009). We include both variables in our QCA models because independent analyses in extant literature have demonstrated the importance of these contextual variables for governance of shared resources in community-managed irrigation systems. Group size increases the transaction costs of and resource mobilization for monitoring and enforcement, but larger groups can mobilize resources (e.g., hiring an official monitor) for rule enforcement (Yang et al. 2013). Hence, it is hard to expect a linear effect of group size on successful self-governance (e.g., Olson 1965, Agrawal and Goyal 2001, Esteban and Ray 2001, Boyd et al. 2010, Tucker 2010). The effect of the resource area is also ambiguous because it is mediated by other attributes of the community such as group size and socioeconomic heterogeneity of farmers (Wade 1989, Ostrom et al. 1994). Irrigation systems that have smaller surface reservoirs to maintain are likely to experience fewer rule infringements compared to those with larger resource areas (Baker 2007). The reason for this is that the larger the resource area (or size of the reservoir), the greater is the expected labor contribution of each household toward maintenance. Based on this literature, we hypothesize that $\mathrm{HH}$ is a key contextual variable for examining the relevance of rules for (1) monitoring one another's behavior (DP4A) and (2) sanctioning rules (DP5), and ARHH is a key variable for examining rules for (1) monitoring the condition of the resource (DP4B), and (2) maintaining congruence between appropriation and provision (DP2B). Our QCA results are generated under the assumption that the directions of the effects of these contextual conditions on self-governance are not deterministic. The 11 DPs were coded as 1 ("presence") or 0 ("absence") for each village. The two contextual variables were calibrated into a continuous scale of 0.0-1.0. See Appendix Fig. A1.2 and Fig. A1.3 for more details on the two contextual variables and their calibration.

\section{RESULTS}

We conceptualize three models to examine how institutional arrangements vary across cases and with contextual conditions. Model 1 analyzes co-occurrences of DPs and relates successful self-governance to these institutional conditions across all cases. Models 2 and 3 examine how different contextual conditions ( $\mathrm{HH}$ and ARHH) affect the combinations of DPs leading to success in all cases. The three models that we use for the fsQCA analysis are the following:

Model 1: SUCCESS =

$f(\underline{D P 1 A}, D P 1 B, D P 2 A, D P 2 B, D P 3, D P 4 A, D P 4 B, D P 5, D P 6, D P 7, D P 8)$

institutional conditions

Model 2: SUCCESS =

$f(\underbrace{H H}, D P 1 A, D P 1 B, D P 2 A, D P 2 B, D P 3, D P 4 A, D P 4 B, D P 5, D P 6, D P 7, D P 8)$ contextual condition institutional conditions

Model 3: SUCCESS =

$f(\quad A R H H \quad, D P 1 A, D P 1 B, D P 2 A, D P 2 B, D P 3, D P 4 A, D P 4 B, D P 5, D P 6, D P 7, D P 8)$ contextual condition institutional conditions 
Table 2. Measures of biophysical and social outcomes and overall success.

Biophysical outcomes

Resource

Physical infrastructure

Assessed as "good" (coded as "1") unless resource balance (BEGBLNC and ENDBLNC) has become worse. The measure of

NATINFRACOND was used only for a case with N/A of BEGBLNC and ENDBLNC. In this case, resource outcome is assessed as "good" unless natural infrastructure condition has become worse.

BEGBLNC: Balance between quantities of units withdrawn and those available 15-20 years ago;

ENDBLNC: Balance between quantities of units withdrawn and those available at present;

NATINFRACOND: Changes in condition of natural infrastructure during this period;

Assessed as "good" (coded as "1") unless two or more of public appropriation, distribution, and production infrastructure have become worse BEGCONDA: Public appropriation infrastructure 15-20 years ago ;

ENDCONDA: Public appropriation infrastructure at present;

BEGCONDD: Public distribution infrastructure maintenance 15-20 years ago

ENDCONDD: Public distribution infrastructure maintenance at present;

BEGCONDP: Public production infrastructure maintenance 15-20 years ago;

ENDCONDP: Public production infrastructure maintenance at present;

Social outcomes

Human infrastructure

Trust

Assessed as "good" (coded as "1") unless human infrastructure condition (e.g., skill and knowledge) has become worse

HUMINFRACOND: Changes in condition of human infrastructure during this period;

Assessed as "good" (coded as "1") if the level of trust has remained high (BEGTRUST and ENDTRUST) or has improved among appropriators (TRUSTLEVEL)

BEGTRUST: Levels of mutual trust among appropriators 15-20 years ago;

ENDTRUST: Levels of mutual trust among appropriators at present;

TRUSTLEVEL: Changes in trust Level during this period;

Rule conformance Assessed as "good" (coded as " 1 ") if about half of the appropriators or more follow the rules formulated by the water user associations/ government/panchayat related to withdrawing and using resource units.

RULEFOLI (16): Behavior of appropriators with respect to rules;

Equity Assessed as "good" (coded as "1") unless there are both disadvantaged (REALOSER) and worse off (WORSTOFF) members.

REALOSER: Appropriators who have been consistently disadvantaged;

WORSTOFF: Worse off been cut off from benefits;

Overall success

Assessed as a success score (0.0-1.0) using a weighted average of biophysical and social outcomes (see Appendix Table A1.2)

More details on each outcome variable (e.g., BEGBLNC) are found in two Coding Manuals at https://seslibrary.asu.edu/resources.

Instead of estimating the linear effects of independent variables on the outcome, the models aim to identify how those conditions are combined with each other in the sample $(\mathrm{N}=50)$ to lead to successful self-governance. DP4B is dropped from our analysis because DP4B is present only in three villages out of 50 (see Fig. 2 and Table A1.3 in Appendix 1), which is too low for inclusion in the models (Rihoux and Ragin 2009). Comparing the different combinations across the three models will help us better understand which DP (or configuration of DPs) makes a robust contribution to successful self-governance despite changes in contextual conditions.

\section{Data description}

Figure 2 shows the distribution of institutional conditions across 50 villages that are determined to have varying degrees of success. We measured a success score of each village (see Table A1.2), then calibrated the success score (see Fig. A1.1). The dataset is skewed toward cases with high success (calibrated score $\geq 0.75$ ), which constitute 37 cases $(74 \%)$ of our sample. There are seven cases with moderate success (calibrated score; $14 \%$ ) and six cases with low success (calibrated score; $12 \%$ ). This may be explained by the bias in our case selection. That is, the communities we selected for this study were already collaborating with FES to help govern their water resources, and thus had fewer cases with failure or low success outcomes. To recap, QCA does not have built-in assumptions that DPs have a positive influence on success; it only allows assumptions regarding the presence or absence of DPs in a given system independent of the outcome. At first glance, the presence or absence of DPs does not appear to follow a pattern. DP4B (accountability of monitors) is present in only three cases.
Fig. 2. Frequency distribution across outcome and the presence of institutional conditions (design principles [DPs]). X-axis represents outcome (degree of success) and 11 institutional conditions (DPs), and Y-axis the number of cases. The outcome is assessed as high success, moderate success, or low success. Ranges of calibrated success score (s) for the outcome are as follows: $\mathrm{s} \geq 0.75$ high success; $0.25<\mathrm{s}<0.75$ for moderate success; and $\mathrm{s} \leq 0.25$ for low success (See Fig A1.1 and Table A1.2 in Appendix 1 for more details on the calibrated success score).

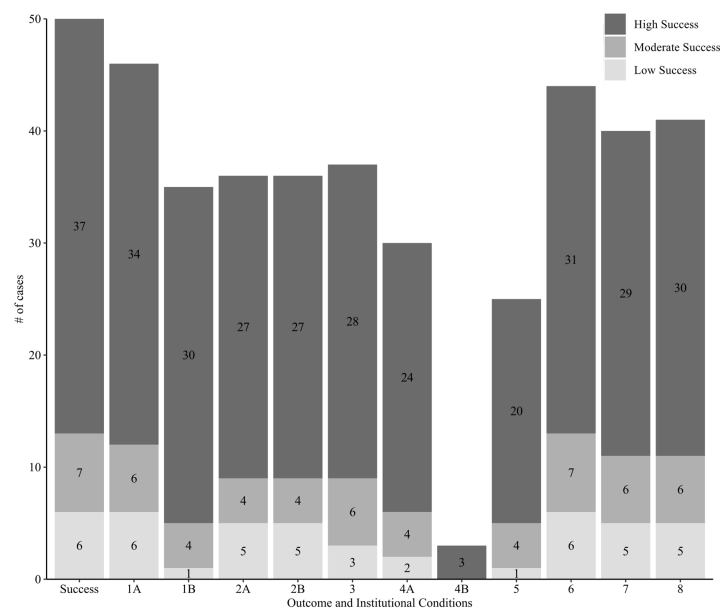


One may speculate that FES functions as an external supervisor of WUAs. The remaining DPs are more likely to be present. Regardless of the presence or absence of specific DPs, we found that increasing the number of institutional conditions is likely to increase the likelihood of high success (see Fig. 2). Cases with high success had an average of 7.9 DPs, while moderate success had an average of 6.5 DPs and low success had an average of 5.7 DPs. The two cases with 11 DPs present both had high success outcomes.

Simple univariate analysis of Figures 2 and 3 does not show obvious patterns of co-occurrence of DPs, or answer questions like "does the presence of specific DP configurations increase the likelihood of successful outcomes?" Therefore, we draw on Baggio et al. (2016) to analyze the co-occurrence of DPs. Fig. 4-A shows the co-occurrence of DPs in villages with moderate success and low success outcomes. Fig. 4-B shows the co-occurrence of DPs in villages with high success outcomes. We normalized the frequency of co-occurrence of DPs by dividing the frequency of DPs by the total number of cases to compare results of villages with weak membership in the set of successful villages and those with a strong membership in the set.

Fig. 3. Number of institutional conditions (design principles [DPs]) present in cases with different success outcomes. X-axis represents the number of institutional conditions (DPs) present in a case, and Y-axis the number of cases. The outcome is assessed as high success, moderate success, or low success.

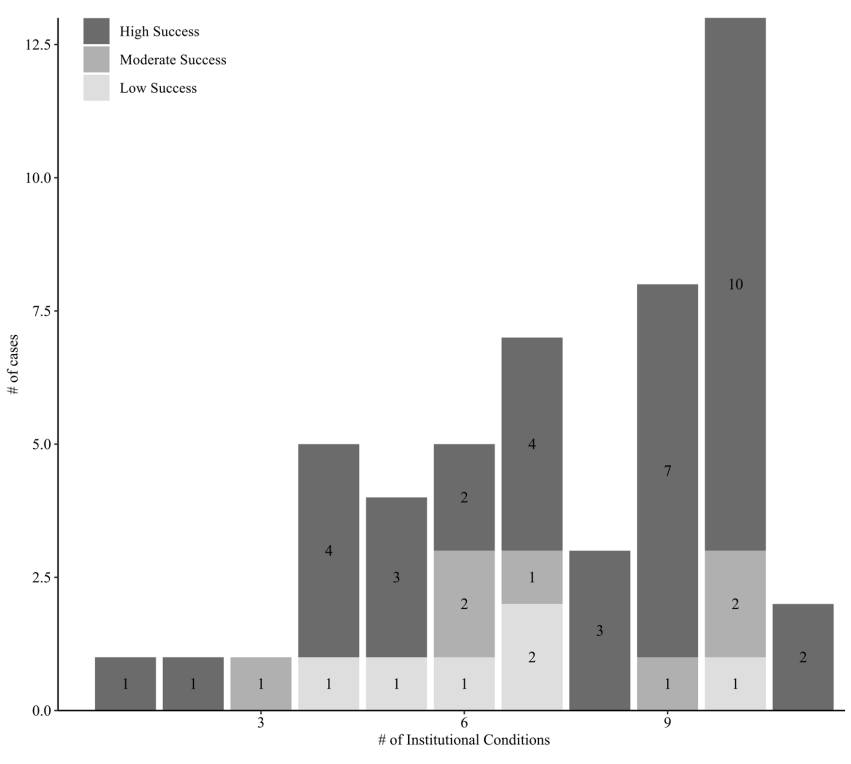

Although there is co-occurrence in villages with both strong and weak memberships, there are a few interesting observations within each set. Clearly defined social boundaries (1A) is likely to occur in both sets of villages, but clearly defined biophysical boundaries (1B) is likely to co-occur with DP1A in villages with high success outcomes. Interestingly, congruence rules ( $2 \mathrm{~A}$ and $2 \mathrm{~B})$ co-occur in both sets but have a marginally higher likelihood of cooccurrence in the set of villages with medium and low success outcomes. Clearly defined boundaries (1A and 1B), collectivechoice arrangements (3), and monitoring (4A) are more likely to co-occur in the villages with high success outcomes. This result mirrors the findings of Baggio et al. (2016) on the co-occurrence of these groups of DPs in cases with successful outcomes. When these core conditions are present, graduated sanctions (5), conflict resolution mechanisms (6), and minimal rights to organize (7) are less likely to exist in these villages. On the other hand, clearly defined social boundaries (1A), conflict resolution mechanisms (6), and minimal rights to organize (7), and nested enterprises (8) are highly likely to co-occur in villages with weak membership in the successful set. This analysis is useful in illustrating strong (and weak) co-occurrences of all DPs. However, the differences in these patterns can be driven by key differences in the attributes of villages, such as group size and size of the source being managed. Moreover, this analysis does not relate different configurations of DPs to success outcomes. This raises the need for further analysis of the configurations of DPs using QCA, which we present below.

Fig. 4. Co-occurrence of design principles (DPs). (A) Villages with weak membership in the set of successful villages (moderate and low success outcomes). (B) Villages with strong membership in the set of successful villages (high success outcomes). Color (represented by the legend on the right) indicates frequency of DP co-occurrence scaled between 0 (bright red; never co-occur) to 1 (bright blue; always co-occur). DPs always co-occur with themselves; therefore, the diagonal is bright blue (frequency $=1$ ).

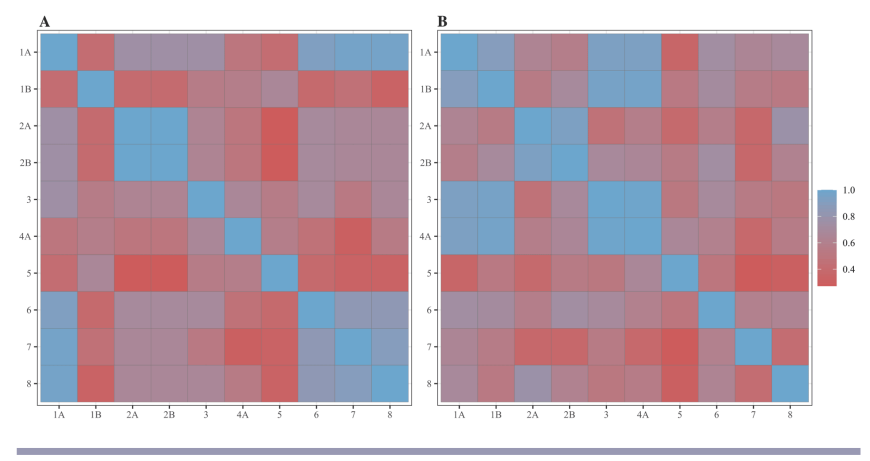

Combinations of institutional and contextual conditions

As recommended by Ragin (2008), we based our combinations on the intermediate solution that requires us to use theoretical and substantive knowledge about the influence of each condition on the outcome. Based on the discussion on group size and resource area above, we expected that $\mathrm{HH}$ (group size) and ARHH (resource area) could contribute to successful self-governance when it is present or absent, and that DPs could contribute to this outcome when they are present. Using these directional expectations, the fsQCA software 3.0 (Ragin and Davey 2016) computed the intermediate solution. The frequency cutoff was set to 2 in all the three models. The consistency cutoff is 0.822 , 0.892, and 0.849 in Model 1, 2, and 3, respectively.

Each fsQCA model reports its own solution formula consisting of one or multiple combinations. Table 3 shows that Model 1 generates a single combination of institutional conditions $(\mathrm{C} 1)$, Model 2 three combinations (C2, C3, and C4), and Model 3 two combinations (C5 and C6). In Model 1, C1 suggests that if a village established all the DPs (except for DP7), the village can be 
Table 3. The simplified solution formula. The weak membership is emphasized in bold "hh" and "arhh."

\begin{tabular}{|c|c|c|c|}
\hline \multicolumn{4}{|c|}{ Outcome: successful self-governance } \\
\hline & Combinations of conditions (Intermediate solution) ${ }^{\dagger}$ & Consistency & Raw Coverage \\
\hline$\overline{\text { Model } 1}$ & (C1) DP1A*DP1B*DP2A*DP2B*DP3*DP4A*DP5*DP6*DP8 & 0.838 & 0.387 \\
\hline \multirow[t]{3}{*}{ Model 2} & (C2) hh*DP1A*DP1B*DP2A*DP2B*DP3*DP4A*DP5*DP6*DP8 + & 0.899 & 0.279 \\
\hline & (C3) hh*DP1A*DP1B*DP2A*DP2B*DP3*DP4A*DP6*DP7*DP8 + & 0.904 & 0.304 \\
\hline & (C4) DP1A*DP1B*DP2A*DP2B*DP3*DP4A*DP5*DP6*DP7*DP8 & 0.822 & 0.316 \\
\hline \multirow[t]{2}{*}{ Model 3} & (C5) arhh*DP1A*DP1B*DP2A*DP2B*DP3*DP4A*DP5*DP6*DP8 + & 0.869 & 0.291 \\
\hline & (C6) DP1A*DP1B*DP2A*DP2B*DP3*DP4A*DP5*DP6*DP7*DP8 & 0.822 & 0.316 \\
\hline
\end{tabular}

- Acronyms: DP (presence of design principle); HH (large group size); ARHH (large resource area per household)

- Lowercase characters represent weak membership in the set of villages with large group size (hh) and with large resource area per household (arhh). Boldface letters emphasize two contextual conditions (group size and resource area).

- The symbol of "+" represents the logical operator OR and the "*" represents AND.

Model 1: Solution coverage $=0.387 ;$ Solution consistency $=0.838$

Model 2: Solution coverage $=0.449 ;$ Solution consistency $=0.852$

Model 3: Solution coverage $=0.366 ;$ Solution consistency $=0.841$

'See Table A1.5 in Appendix 1 for cases with greater than 0.5 membership in each solution term.

Raw coverage measures the proportion of memberships in the outcome explained by each solution term. This measure is calculated by dividing the sum of consistent membership in the solution term by the sum of membership in the outcome (Ragin and Davey 2016).

successful in self-governance. DP7 (minimal recognition of rights to organize) was found to be irrelevant to successful selfgovernance in the sample. In Model 2, C2 and C3 present two different combinations of DPs that are likely to lead to successful self-governance if a village has weak membership in the set of villages with a large group size. These two combinations are identical, except that $\mathrm{C} 2$ has graduated sanctions and $\mathrm{C} 3$ has minimal recognition of the rights to organize. The weak membership is emphasized by boldface " $\mathrm{hh}$ " in Table 3 . The last combination in Model 2 is C4 consisting of only DPs. This signifies that if there are all DPs in a village, it will be successful regardless of the group size. Such a full combination of DPs is also found in Model 3: C6 is identical to C4. C6 reports that with all DPs present, a village can be successful regardless of the resource area. C5 is another combination in Model 3, suggesting an institutional combination that will likely lead to success if a village has weak membership in the set of villages with a large resource area per household. The weak membership is emphasized by boldface "arhh" in Table 3 .

Our sample size of 50 communities is far lower than the number of logically possible combinations of institutional conditions in the three proposed models. For example, in Model 1, assuming each of the 10 DPs could be either present or absent, a total of 1024 combinations of DPs are possible. It is highly likely that no empirical information may be found on several of these combinations or outcomes (Schneider and Wagemann 2012). This challenge, which is often referred to as the limited diversity of empirical observations, may be addressed by running robustness checks on the assumptions of presence or absence of each condition and its directionality effect (positive or negative) on the outcome (Ragin 2008, Rihoux and De Meur 2009, Schneider and Wagemann 2012). In our analysis, we first assumed that the presence of each DP contributes to successful self-governance (see Table 3). Then, we checked the robustness of our results by assuming that each DP contributes to the same outcome when it is either present or absent (see Table A1.6). The results of the robustness tests are the same as our first analysis.
fsQCA reports two set-theoretic measures (consistency and coverage) for assessing how strongly a set relation between a combination and a given outcome is supported by empirical cases (Ragin 2008). Both measures are shown in Table 3. Consistency assesses the degree to which a combination of conditions is a subset of the outcome. A combination with a high-score consistency implies the combination is a more reliable sufficient condition for the outcome. Raw coverage assesses how much of the outcome is explained by a combination of conditions, and hence indicates the solution term is empirically more relevant. However, high coverage does not always imply the solution term is theoretically more important. For instance, high coverage paths could not contribute to generating new theoretical knowledge if they are too obvious (Grofman and Schneider 2009, Schneider and Wagemann 2010). The aim of this study is to produce theoretical and substantive knowledge about how combinations of DPs vary with presence/absence of and kinds of contextual conditions. Therefore, we compare all the combinations $(\mathrm{C} 1$ to C6) generated by Model 1, 2, and 3.

\section{DISCUSSION}

In this paper, we examine the institutional foundations of adaptive water governance that can foster flexibility and adaptation among individuals to respond to environmental and social stressors. One way that institutions can promote flexibility is through improving the capacity of those whose livelihoods depend on the affected water resources to self-organize and address resource-related challenges (Dietz et al. 2003, DeCaro et al. 2017). In doing so, institutions allow for individuals to adapt rules based on changing socioeconomic and environmental conditions. The institutional foundations we examine in this study are based on communitybased environmental governance research. Specifically, we draw on Elinor Ostrom's well-known institutional DPs to examine how local WUAs influence societal capacity to solve complex problems (Ostrom 1990, 2010, Shivakumar 2005).

Comparison of all the fsQCA combinations shows that the presence of DP $1 \mathrm{~A}, 1 \mathrm{~B}, 2 \mathrm{~A}, 2 \mathrm{~B}, 3,4 \mathrm{~A}, 6$, and 8 are necessary (but 
not sufficient) conditions for successful self-governance. In other words, self-governance will not be successful in the absence of these DPs, regardless of contextual conditions (HH and ARHH). However, the extent to which DPs can foster self-governance is contingent on the contextual conditions within which they are embedded. We must therefore understand how these institutions affect outcomes in different conditions to assess the effectiveness of DPs in social-ecological systems (Young 2002, Ostrom 2010).

\section{Robustness of all-DPs-presence to contextual changes: $\mathrm{C} 4$ and C6}

The solution terms C4 and C6 indicate a sufficient set relation showing that self-governance will be successful if all the DPs are present. Interestingly, the all-DPs-presence (ADP) combination is not observed in Model 1, which does not include contextual conditions. The ADP combination is observed only in Models 2 and 3, which include different contextual conditions. This result provides two theoretical insights into CPR studies on the configural nature of DPs. First, the sufficient set relation (i.e., ADP) is robust to changes in group size $(\mathrm{HH})$ and resource area (ARHH). This means that ADP is likely to lead to successful selfgovernance regardless of whether group size is large or whether resource area is large. Although we examine a limited set of contextual conditions in this study, we found that the ADP combination may produce successful self-governance despite changes in contextual variables. The second key insight from examining the solution term $\mathrm{C} 1$ is that the ADP combination is not observed in Model 1. To recap, Model 1 examines only the institutional conditions (DPs) and does not include the contextual variables $(\mathrm{HH}$ and $\mathrm{ARHH})$ in which they are embedded. Therefore, a comparison of $\mathrm{C} 1$ with $\mathrm{C} 4$ and $\mathrm{C} 6$ demonstrates that the maximum configural nature of DPs can emerge only when institutions interact with other relevant contextual conditions.

Results from fsQCA analysis confirm our observations from interviews and discussions with farmers. For example, consider Malmotakapalle $(\mathrm{HH}=20, \mathrm{ARHH}=4.65)$, Guttakindapalle Thanda $(\mathrm{HH}=75, \mathrm{ARHH}=0.8), \mathrm{M}$.Vyapalapalle $(\mathrm{HH}=189$, $\mathrm{ARHH}=3.46)$, and Nagamvaripalle $(\mathrm{HH}=35, \mathrm{ARHH}=22.86)$. All these villages have the ADP combination, with varying degrees of successful outcomes, i.e., the first three villages have highly successful outcomes whereas Nagamvaripalle has relatively weaker membership in the set of successful villages (Fig. 3; also see calibrated success score in Appendix 1, Fig. A1.1). This may be attributed to the larger resource area in Nagamvaripalle. Discussions with the villagers indicated that even though the WUA actively enforces monitoring rules, they often struggle with checking maintenance efforts of farmers because of the large area of the reservoir, resulting in poor infrastructure quality. Simply put, context matters: the effect of DPs on outcomes is mediated by contextual variables. Our results strongly support the argument that DPs can create sufficient opportunities for robust cooperation (Ostrom 1990, McGinnis and Ostrom 2014), facilitate emergence of adaptive governance (Dietz et al. 2003), and reinforce the importance of group size and resource area in managing irrigation systems (Ostrom et al. 1994, Shin et al. 2020, Vallury et al. 2020).

\section{Vulnerability of $\mathrm{C} 1$ to contextual conditions: $\mathrm{C1}, \mathrm{C2}$, and $\mathrm{C5}$} The combination of DPs shown in C1 (Model 1) also appears in C2 (Model 2) and C5 (Model 3). Based on this observation, one can say that the institutional combination (DP1A*DP1B*DP2A* $\left.\mathrm{DP} 2 \mathrm{~B} * \mathrm{DP} 3 * \mathrm{DP} 4 \mathrm{~A}^{*} \mathrm{DP} 5 * \mathrm{DP} 6 * \mathrm{DP} 8\right)$ is linked to successful selfgovernance and robust to changes in contextual conditions. However, a close look at solution terms $\mathrm{C} 2$ and $\mathrm{C} 5$ reveals that their combination of DPs is likely to lead to successful selfgovernance only in villages with weak membership in the set of villages with a large group size or resource areas, represented as "hh" in C2 and "arhh" in C5. Such contextually constrained capability of producing the outcome implies that this institutional condition is likely to result in successful self-governance only in villages with a small group size or resource areas.

An interesting observation from $\mathrm{C} 1, \mathrm{C} 2$, and $\mathrm{C} 5$ is the absence of rights to organize (DP7). The methodological rationale for this can be attributed to fsQCA's process of gaining logically minimal combinations of conditions (Ragin 2017). fsQCA uses Boolean algebra to compare across cases and deduces a minimal set of conditions that are necessary for an outcome. In our data, successful outcomes were observed in villages with and without DP7 if all the remaining DPs were present (see Table A1.1 in Appendix 1). As a result, fsQCA eliminated DP7 from the solution terms.

The presence of DP7 indicates that the rights of farmers to devise their own institutions for managing their irrigation resources are not challenged by external authorities. DP7 is indicative of the relationship between the government and farmers, making it an important determinant of successful self-governance of natural resources (e.g., Pelling 1998, Adger 2003, Barnett and Eakin 2015). Institutional design principles that minimize external intervention and facilitate stakeholders' rights to organize can ultimately generate conditions for procedural fairness, legitimacy, and security needed to cultivate trust and cooperation (DeCaro et al. 2017). Moreover, these conditions improve the opportunities for adaptation (Craig and Ruhl 2014), and the scope for adaptive governance to emerge within rigid governance systems (Bingham et al. 2005). Even though DP7 is missing from the fsQCA solution terms, our analysis reveals interesting co-occurrence patterns between DP7 and other DPs.

The co-occurrence of clearly defined social boundaries (1A) with rights to organize (7) and nested enterprises (8) in less successful villages can be interpreted as evidence of the feedback between governments and irrigation communities (Fig. 4-A). It is important to note that the political context in Karnataka and Andhra Pradesh plays a key role in how WUAs operate in irrigation communities and institutions for resource governance are designed. We found that panchayats (formal village councils) and the District Magistrate's office had more administrative control over the functioning of WUAs in Karnataka. That is, irrigation officials issued directives for water allocation and infrastructure maintenance rules based on water availability in the region. On the other hand, WUAs in Andhra Pradesh have more autonomy, and thereby flexibility, in collectively designing rules for managing their irrigation resources. Interestingly, several villages from Karnataka with small resource areas in our dataset showed high likelihood of the co-occurrence of DP7 and DP8, but reported less successful outcomes (e.g., Srirampura, Donakonda, and Kondappagarihalle; see Fig 4-A and Table A1.3 in Appendix 1). Barnett and Anderies (2014) hypothesized that the combination of social-ecological boundaries (1A and 1B) and 
rights to organize (7) can mutually reinforce each other and improve resource outcomes. Our results cannot confirm this hypothesis because DPs $1 \mathrm{~A}$ and 7 have a higher co-occurrence in villages with less successful outcomes in our data. However, our results seem to suggest that when these institutional design principles co-occur, their effectiveness is mediated by contextual conditions like resource area and group size.

\section{Irrelevance of graduated sanctions to successful self-governance: C3}

The solution term C3 shows that DP5 (graduated sanctions) is irrelevant to successful self-governance if the other DPs are present in villages with weak membership in the set of villages with large numbers of households. Note that among all six combinations in Table 3, C3 is the only one without DP5. This means that the irrelevance of graduated sanctions to successful self-governance is not frequently observed in the sample at hand and can be true only if the weak membership (" $\mathrm{hh}$ ") is met. Although we can explain why DP5 is irrelevant in the methodological point of view, it is difficult to pinpoint the exact, substantive reason for the irrelevance because of the lack of detailed information on sanctions. One possible reason is that graduated sanctioning is so costly that people can choose not to establish DP5 in villages with a small group size (Boyd et al. 2018, Shin et al. 2020). Besides the close relationship between farmers in a small village, the role of village leaders in settling disputes among resource users could also contribute to the absence of DP5. Lam and Ostrom (2010) note that in agricultural communities where farmers hesitate to punish rule violators, graduated sanctioning could be replaced with the presence of active arbitrators.

\section{CONCLUSION}

Elinor Ostrom's work on institutional analysis stresses the significance of devising formal and informal institutions to facilitate self-organizing agents and adaptive governance in social-ecological systems (Ostrom 2005, Cole and McGinnis 2014). Our aim in this study was to examine how institutional DPs, like internal mechanisms for dispute resolution, monitoring, and enforcement, affect outcomes like trust, self-organization, and participatory decision making needed to cultivate trust and promote cooperation in complex social-ecological dilemmas. We used three different fsQCA models of self-governing irrigation systems and compared the model results to investigate how combinations of DPs leading to successful self-governance are shaped by social and biophysical contexts. If generalized more broadly, these DPs and contextual conditions, and perhaps other principles (DeCaro et al. 2017), can establish a set of institutional foundations that can guide and support adaptive governance of water resources.

Our fsQCA results presented three key findings about the interaction between adaptive governance institutions (DPs) and contextual conditions. First, if DPs are considered in isolation from contextual conditions (Model 1), the all-DPs-presence (ADP) combination (i.e., C4 and C6) does not appear as a sufficient set relation leading to successful self-governance. Only when DPs are coupled with social and biophysical contexts (Model 2 and 3), the ADP combination is likely to lead to successful self-governance. Furthermore, the ADP combination turns out to be robust to changes in contextual conditions because it appears regardless of whether group size is large or whether resource area is large. Second, the institutional combination without DP7 (rights to organize) is also likely to lead to successful self-governance. However, this combination consisting of $\mathrm{C} 1, \mathrm{C} 2$, and $\mathrm{C} 5$ is vulnerable to changes in contextual conditions because, in Model 2 and 3, it can generate successful self-governance outcomes only when group size or resource area is small. The last combination in C4 shows that DP5 (graduated sanctioning) is irrelevant to successful self-governance if group size is small. Other empirical studies also report that successful CPR cases often lacked graduated sanctioning, which could entail a high cost of rule enforcement or be replaced with conflict mechanisms (e. g., Lam and Ostrom 2010, Boyd et al. 2018, Shin et al. 2020).

A key challenge in extant adaptive governance literature is the limited focus on institutions that support such adaptation without constraining stakeholders' inherent capacity to self-organize (DeCaro et al. 2017). Our study addresses this problem by analyzing how existing institutions can create favorable conditions for adaptation, across multiple resource settings. We build on prior work by integrating theories of self-governance (Ostrom 1990), adaptive law (Craig and Ruhl 2014), and statereinforced self-governance (Sarker 2013). We explicitly demonstrate how contextual conditions may shape the degree to which institutional design principles can facilitate adaptive governance. These design principles, which are based on Ostrom's theory of self-governance (Cox et al. 2010) are non-exhaustive but demonstrate important ways in which decision makers can create enabling conditions for adaptation. Future work needs to investigate if and how these design principles translate to more diverse social-ecological contexts and facilitate adaptive governance of shared resources. Furthermore, the methodological approaches developed in this article are intended to provide vital guidance for future research.

Our focus on utilizing primary data cases is fruitful to identify causal chains that explain how the DPs affected outcomes and the relationship between DPs and local contexts. There were, however, a few limitations to our approach. First, our sample is limited to the irrigation communities where FES assisted in designing operational and collective-choice level rules that facilitate self-organization of farmers, raising concern of potential selection bias underlying the large portion of our sample qualifying as highly successful. Increasing our sample size by collaborating with multiple practitioner organizations could have potentially helped reduce sampling bias. Such collaboration, albeit more expensive, would have also helped us collect data from irrigation communities in multiple districts across both the states. An increased sample size of this nature could have potentially addressed the challenge of limited diversity of empirical observations. However, we must note that a random selection of more cases may not necessarily remedy the limited diversity of empirical observations because the new cases may contain combinations of DPs that are already observed in our current sample. Second, calculating an intercoder reliability index was unfeasible in our study because it is cost prohibitive to hire multiple field analysts to code the village records. One approach to minimize inconsistencies in interpreting institutional records is to conduct multiple training workshops so that the field staff interpret the coding protocol and village records consistently. Last, even though our analysis assesses how the quality of 
resources, infrastructure, or social outcomes changed over time, they still reflect a series of snapshots of said variables, without explicit consideration of time lags and temporal change. This calls for further investigation through longitudinal studies that identify important contextual factors (Barnett et al. 2016). In spite of these limitations, our methodological approach represents an important step in scaling up data collection efforts to trace the impact of different configurations of DPs on facilitating adaptive governance of resources. Moreover, collaborating with practitioner organizations, such as FES, is important for developing "just enough organization" in local governance, such as WUAs, to adaptively govern their resources (Bruns 1992, Uphoff 2000).

Responses to this article can be read online at: https://www.ecologyandsociety.org/issues/responses. php/12957

\section{Acknowledgments:}

This work received support from the CGIAR Research Program on Water, Land and Ecosystems (WLE), supported by the CGIAR Trust Fund: wle.cgiar.org/donors. Part of this work was completed when the lead author's position was supported by the National Science Foundation under Grant No. 1920938. The authors are also grateful for the logistical support provided by the Foundation for Ecological Security to conduct our fieldwork in South India.

\section{Data Availability:}

The datalcode that support the findings of this study are available on request from the corresponding author, $S V$.

\section{LITERATURE CITED}

Adger, W. N. 2003. Social capital, collective action, and adaptation to climate change. Economic Geography 79 (4):387-404.

Agrawal, A., and S. Goyal. 2001. Group size and collective action: third-party monitoring in common-pool resources. Comparative Political Studies 34(1):63-93. https://doi.org/10.1177/0010414001034001003

Arnold, C. A., and L. H. Gunderson. 2013. Adaptive law and resilience. Environmental Law Reporter News \& Analysis 43:10426.

Baggio, J., A. Barnett, I. Perez-Ibarra, U. Brady, E. Ratajczyk, N. Rollins, C. Rubiños, H. Shin, D. Yu, R. Aggarwal, J. M. Anderies, and M. A. Janssen. 2016. Explaining success and failure in the commons: the configural nature of Ostrom's institutional design principles. International Journal of the Commons 10(2):417-439. https://doi.org/10.18352/ijc.634

Baker, J. M. 2007. The Kuhls of Kangra: community-managed irrigation in the western Himalaya. University of Washington Press, Seattle, Washington, USA.

Barnett, A. J., and J. M. Anderies. 2014. Weak feedbacks, governance mismatches, and the robustness of social-ecological systems: an analysis of the southwest Nova Scotia lobster fishery with comparison to Maine. Ecology and Society 19(4):39. https:// doi.org/10.5751/ES-06714-190439

Barnett, A., J. Baggio, H. Shin, D. Yu, I. Perez-Ibarra, C. Rubiños, U. Brady, E. Ratajczyk, N. Rollins, R. Aggarwal, J. M. Anderies, and M. A. Janssen. 2016. An iterative approach to case study analysis: insights from qualitative analysis of quantitative inconsistencies. International Journal of the Commons 10 (2):467-494. https://doi.org/10.18352/ijc.632

Barnett, A. J., and H. C. Eakin. 2015. "We and us, not I and me": justice, social capital, and household vulnerability in a Nova Scotia fishery. Applied Geography 59:107-116. https://doi. org/10.1016/j.apgeog.2014.11.005

Bingham, L. B., T. Nabatchi, and R. O'Leary. 2005. The new governance: practices and processes for stakeholder and citizen participation in the work of government. Public Administration Review 65(5):547-558. https://doi.org/10.1111/j.1540-6210.2005.00482. $\underline{\mathrm{X}}$

Boyd, R., H. Gintis, and S. Bowles. 2010. Coordinated punishment of defectors sustains cooperation and can proliferate when rare. Science 328(5978):617-620. https://doi.org/10.1126/ science. 1183665

Boyd, R., P. J. Richerson, R. Meinzen-Dick, T. De Moor, M. O. Jackson, K. M. Gjerde, H. Harden-Davies, B. M. Frischmann, M. J. Madison, K. J. Strandburg, A. R. McLean, and C. Dye. 2018. Tragedy revisited. Science 362(6420):1236-1241. https://doi. org/10.1126/science.aaw0911

Bruinsma, J. 2017. World agriculture: towards 2015/2030: an FAO perspective. Routledge, London, UK. https://doi. org/10.4324/9781315083858

Bruns, B. R. 1992. Just enough organization: water users' associations and episodic mobilization. Visi: Irigasi Indonesia 6:33-41.

Carpenter, J. P. 2007. Punishing free-riders: how group size affects mutual monitoring and the provision of public goods. Games and Economic Behavior 60(1):31-51. https://doi.org/10.1016/j. geb.2006.08.011

Chaffin, B. C., H. Gosnell, and B. A. Cosens. 2014. A decade of adaptive governance scholarship: synthesis and future directions. Ecology and Society 19(3):56. https://doi.org/10.5751/ES-06824-190356

Chaffin, B. C., and L. H. Gunderson. 2016. Emergence, institutionalization and renewal: rhythms of adaptive governance in complex social-ecological systems. Journal of Environmental Management 165:81-87. https://doi.org/10.1016/j.jenvman.2015.09.003

Clarvis, M. H., A. Allan, and D. M. Hannah. 2014. Water, resilience and the law: from general concepts and governance design principles to actionable mechanisms. Environmental Science and Policy 43:98-110. https://doi.org/10.1016/j envsci.2013.10.005

Cole, D. H., and M. D. McGinnis. 2014. Elinor Ostrom and the Bloomington School of Political Economy, Volume 1: Polycentricity in Public Administration and Political Science. Lexington Books, Lanham, Maryland, USA. 
Cosens, B. A., R. K. Craig, S. L. Hirsch, C. A. (T.) Arnold, M. H. Benson, D. A. DeCaro, A. S. Garmestani, H. Gosnell, J. Ruhl, and E. Schlager. 2017. The role of law in adaptive governance. Ecology and Society 22(1):30. https://doi.org/10.5751/ES-08731-220130

Cosens, B., L. Gunderson, and B. Chaffin. 2014. The adaptive water governance project: assessing law, resilience and governance in regional socio-ecological water systems facing a changing climate. Idaho Law Review 51:1.

Cox, M., G. Arnold, and S. Villamayor Tomás. 2010. A review of design principles for community-based natural resource management. Ecology and Society 15(4):38. https://doi. org/10.5751/ES-03704-150438

Craig, R. K., A. S. Garmestani, C. R. Allen, C. A. T. Arnold, H. Birgé, D. A. DeCaro, A. K. Fremier, H. Gosnell, and E. Schlager. 2017. Balancing stability and flexibility in adaptive governance: an analysis of tools available in U.S. environmental law. Ecology and Society 22(2):3. https://doi.org/10.5751/ES-08983-220203

Craig, R. K., and J. B. Ruhl. 2014. Designing administrative law for adaptive management. Vanderbilt Law Review 67:1. https:// doi.org/10.2139/ssrn.2222009

DeCaro, D. A., B. C. Chaffin, E. Schlager, A. S. Garmestani, and J. B. Ruhl. 2017. Legal and institutional foundations of adaptive environmental governance. Ecology and Society 22(1):32. https:// doi.org/10.5751/ES-09036-220132

Dietz, T., E. Ostrom, and P. C. Stern. 2003. The struggle to govern the commons. Science 302(5652):1907-1912. https://doi. org/10.1126/science.1091015

Dietz, T., E. A. Rosa, and R. York. 2009. Environmentally efficient well-being: rethinking sustainability as the relationship between human well-being and environmental impacts. Human Ecology Review 16:114-123.

Directorate of Economics \& Statistics. 2018. Agricultural statistics at a glance 2017-18. Directorate of Economics \& Statistics, Andhra Pradesh, India. [online] URL: https://www. core.ap.gov.in/cmdashboard/Download/Publications/Agrl. $\% 20$ at $\%$ 20a\%20Glance $\% 202017-18$-Provisional.pdf

Edwards, V., and N. Steins. 1999. A framework for analysing contextual factors in common pool resource research. Journal of Environmental Policy and Planning 1(3):205-221. https://doi. org/10.1080/714038536

Epstein, G., J. Pittman, S. M. Alexander, S. Berdej, T. Dyck, U. Kreitmair, K. J. Rathwell, S. Villamayor-Tomas, J. Vogt, and D. Armitage. 2015. Institutional fit and the sustainability of socialecological systems. Current Opinion in Environmental Sustainability 14:34-40. https://doi.org/10.1016/j.cosust.2015.03.005

Esteban, J., and D. Ray. 2001. Collective action and the group size paradox. American Political Science Review 95:663-672. https:// doi.org/10.1017/S0003055401003124

Fiss, P. C., D. Sharapov, and L. Cronqvist. 2013. Opposites attract? Opportunities and challenges for integrating large-N QCA and econometric analysis. Political Research Quarterly 66:191-198.
Folke, C., T. Hahn, P. Olsson, and J. Norberg. 2005. Adaptive governance of social-ecological systems. Annual Review of Environment and Resources 30:441-473. https://doi.org/10.1146/ annurev.energy.30.050504.144511

Folke, C., L. Pritchard Jr, F. Berkes, J. Colding, and U. Svedin. 2007. The problem of fit between ecosystems and institutions: ten years later. Ecology and Society 12(1):30. https://doi.org/10.5751/ ES-02064-120130

Groenfeldt, D., and J. J. Schmidt. 2013. Ethics and water governance. Ecology and Society 18(1):14. https://doi. org/10.5751/ES-04629-180114

Grofman, B., and C. Q. Schneider. 2009. An introduction to crisp set QCA, with a comparison to binary logistic regression. Political Research Quarterly 62(4):662. https://doi.org/10.1177/1065912909338464

Gunderson, L. H., C. S. Holling, and S. Light. 1995. Barriers and bridges to the renewal of ecosystems. Columbia University Press, New York, New York, USA.

Hill, M. 2013. A starting point: understanding governance, good governance and water governance. Pages 17-28 Climate change and water governance. Springer, Dordrecht, The Netherlands. https://doi.org/10.1007/978-94-007-5796-7_2

Hurlbert, M. A., and H. Diaz. 2013. Water governance in Chile and Canada: a comparison of adaptive characteristics. Ecology and Society 18(4):61. https://doi.org/10.5751/ES-06148-180461

Hurlbert, M. A., and J. Gupta. 2019. An institutional analysis method for identifying policy instruments facilitating the adaptive governance of drought. Environmental Science and Policy 93:221-231. https://doi.org/10.1016/j.envsci.2018.09.017

Isaac, R. M., J. M. Walker, and A. W. Williams. 1994. Group size and the voluntary provision of public goods: experimental evidence utilizing large groups. Journal of Public Economics 54 (1):1-36. https://doi.org/10.1016/0047-2727(94)90068-X

Jordan, E., M. E. Gross, A. N. Javernick-Will, and M. J. Garvin. 2011. Use and misuse of qualitative comparative analysis. Construction Management and Economics 29(11):1159-1173. https://doi.org/10.1080/01446193.2011.640339

Knieper, C., G. Holtz, B. Kastens, and C. Pahl-Wostl. 2010. Analysing water governance in heterogeneous case studiesexperiences with a database approach. Environmental Science and Policy 13(7):592-603. https://doi.org/10.1016/j.envsci.2010.09.002

Lam, W. F., and E. Ostrom. 2010. Analyzing the dynamic complexity of development interventions: lessons from an irrigation experiment in Nepal. Policy Sciences 43(1):1-25. https:// doi.org/10.1007/s11077-009-9082-6

McGinnis, M. D., and E. Ostrom. 2014. Social-ecological system framework: initial changes and continuing challenges. Ecology and Society 19(2):30. https://doi.org/10.5751/ES-06387-190230

Mosse, D. 2006. Collective action, common property, and social capital in South India: an anthropological commentary. Economic Development and Cultural Change 54(3):695-724. https://doi.org/10.1086/500034 
Olson, M. 1965. Logic of collective action: public goods and the theory of groups. Harvard University Press, Cambridge, Massachusetts, USA.

Ostrom, E. 1990. Governing the commons: the evolution of institutions for collective action. Cambridge University Press, Cambridge, UK. https://doi.org/10.1017/CBO9780511807763

Ostrom, E. 2005. Understanding institutional diversity. Princeton University Press, Princeton, New Jersey, USA.

Ostrom, E. 2009. A general framework for analyzing sustainability of social-ecological systems. Science 325 (5939):419-422. https://doi.org/10.1126/science.1172133

Ostrom, E. 2010. Polycentric systems for coping with collective action and global environmental change. Global Environmental Change 20(4):550-557. https://doi.org/10.1016/j.gloenvcha.2010.07.004

Ostrom, E. 2014. Do institutions for collective action evolve? Journal of Bioeconomics 16(1):3-30. https://doi.org/10.1007/ s10818-013-9154-8

Ostrom, E., W. F. Lam, and M. Lee. 1994. The performance of self-governing irrigation systems in Nepal. Human Systems Management 13(3):197-207. https://doi.org/10.3233/HSM-1994-13305

Pahl-Wostl, C. 2019. The role of governance modes and metagovernance in the transformation towards sustainable water governance. Environmental Science and Policy 91:6-16. https:// doi.org/10.1016/j.envsci.2018.10.008

Pahl-Wostl, C., L. Lebel, C. Knieper, and E. Nikitina. 2012. From applying panaceas to mastering complexity: toward adaptive water governance in river basins. Environmental Science and Policy 23:24-34. https://doi.org/10.1016/j.envsci.2012.07.014

Pelling, M. 1998. Participation, social capital and vulnerability to urban flooding in Guyana. Journal of International Development 10(4):469-486. https://doi.org/10.1002/(SICI)1099-1328 (199806)10:4<469::AID-JID539>3.0.CO;2-4

Poteete, A. R., and E. Ostrom. 2004. Heterogeneity, group size and collective action: the role of institutions in forest management. Development and Change 35(3):435-461. https:// doi.org/10.1111/j.1467-7660.2004.00360.x

Ragin, C. C. 2008. Redesigning social inquiry: fuzzy sets and beyond. University of Chicago Press, Chicago, Illinois, USA. https://doi.org/10.7208/chicago/9780226702797.001.0001

Ragin, C. C. 2017. User's Guide to fuzzy-set/qualitative comparative Analysis 3.0.

Ragin, C. C., and S. Davey. 2016. Fuzzy-set/qualitative comparative analysis 3.0.

Ratajczyk, E., U. Brady, J. Baggio, A. Barnett, I. Perez-Ibarra, N. Rollins, C. Rubiños, H. Shin, D. Yu, R. Aggarwal, J. M. Anderies, and M. A. Janssen. 2016. Challenges and opportunities in coding the commons: problems, procedures, and potential solutions in large- $\mathrm{N}$ comparative case studies. International Journal of the Commons 10(2):440-466. https://doi.org/10.18352/ijc.652

Rihoux, B., and G. De Meur. 2009. Crisp-set qualitative comparative analysis (csQCA). Configurational comparative methods: qualitative comparative analysis (QCA) and related techniques. SAGE, Los Angeles, California, USA. https://doi. org/10.4135/9781452226569.n3

Rihoux, B., and C. C. Ragin. 2009. Configurational comparative methods: Qualitative comparative analysis (QCA) and related techniques. SAGE, Los Angeles, California, USA. https://doi. org/10.4135/9781452226569

Ruhl, J. 2010. General design principles for resilience and adaptive capacity in legal systems-with applications to climate change adaptation. North Carolina Law Review 89:1373-1402.

Sarker, A. 2013. The role of state-reinforced self-governance in averting the tragedy of the irrigation commons in Japan. Public Administration 91(3):727-743. https://doi.org/10.1111/padm.12011

Schneider, C. Q., and C. Wagemann. 2010. Standards of good practice in qualitative comparative analysis (QCA) and fuzzy-sets. Comparative Sociology 9(3):397-418. https://doi. org/10.1163/156913210X12493538729793

Schneider, C. Q., and C. Wagemann. 2012. Set-theoretic methods for the social sciences: a guide to qualitative comparative analysis Cambridge University Press, Cambridge, UK. https://doi. org/10.1017/CBO9781139004244

Shin, H. C., D. J. Yu, S. Park, J. M. Anderies, J. K. Abbott, M. A. Janssen, and T. Ahn. 2020. How do resource mobility and group size affect institutional arrangements for rule enforcement? A qualitative comparative analysis of fishing groups in South Korea. Ecological Economics 174:106657. https://doi.org/10.1016/ j.ecolecon.2020.106657

Shivakumar, S. 2005. The constitution of development: crafting capabilities for self-governance. Palgrave Macmillan, New York, New York, USA.

Tucker, C. 2010. Learning on governance in forest ecosystems: lessons from recent research. International Journal of the Commons 4(2):687-706. https://doi.org/10.18352/ijc. 224

Uphoff, N. 2000. Understanding social capital: learning from the analysis and experience of participation. Social capital: A multifaceted perspective 6(2):215-249.

Vallury, S., J. K. Abbott, H. C. Shin, and J. M. Anderies. 2020. Sustaining coupled irrigation infrastructures: multiple instruments for multiple dilemmas. Ecological Economics 178:106793. https:// doi.org/10.1016/j.ecolecon.2020.106793

Villamayor-Tomas, S., C. Oberlack, G. Epstein, S. Partelow, M. Roggero, E. Kellner, M. Tschopp, and M. Cox. 2020. Using case study data to understand SES interactions: a model-centered meta-analysis of SES framework applications. Current Opinion in Environmental Sustainability 44:48-57. https://doi.org/10.1016/ j.cosust.2020.05.002

Wade, R. 1989. Village republics. Cambridge University Press, Cambridge, UK.

Water Resources Department (WRD). 2017. Irrigation in Karnataka. Government of Karnataka, India. [online] URL: http://waterresources.kar.nic.in/irri_in_kar.htm 
Whittaker, D., A. Crippen, C. Johnson, and M. A. Janssen. 2021. Social-ecological institutional fit in volunteer-based organizations: a study of lake management organizations in Vilas County, Wisconsin, USA. International Journal of the Commons 15 (1):181-194. https://doi.org/10.5334/ijc.1059

Yang, W., W. Liu, A. Viña, M.-N. Tuanmu, G. He, T. Dietz, and J. Liu. 2013. Nonlinear effects of group size on collective action and resource outcomes. Proceedings of the National Academy of Sciences 110(27):10916-10921. https://doi.org/10.1073/pnas.1301733110

Young, O. R. 2002. The institutional dimensions of environmental change: fit, interplay, and scale. MIT Press, Cambridge, Massachusetts, USA. https://doi.org/10.7551/ mitpress/3807.001.0001 


\section{Appendix 1}

\section{Table A1.1: Case \# and village information}

\begin{tabular}{|c|c|c|c|c|c|c|c|c|c|}
\hline $\begin{array}{c}\text { Case } \\
\#\end{array}$ & Habitation Name & $\begin{array}{c}\# \text { of } \\
\text { Househol } \\
\text { ds }\end{array}$ & $\begin{array}{c}\text { Resource } \\
\text { Area }\end{array}$ & $\begin{array}{c}\text { Resource } \\
\text { Area per } \\
\text { Household }\end{array}$ & $\begin{array}{c}\text { Case } \\
\#\end{array}$ & Habitation Name & $\begin{array}{c}\# \text { of } \\
\text { Household } \\
\text { s }\end{array}$ & $\begin{array}{c}\text { Resource } \\
\text { Area }\end{array}$ & $\begin{array}{c}\text { Resource } \\
\text { Area per } \\
\text { Household }\end{array}$ \\
\hline 1 & Ammagaripeta & 165 & 7 & 0.04 & 26 & Pothulavandlapalle & 59 & 500 & 8.47 \\
\hline 2 & Bodyreddypalle & 31 & 78 & 2.52 & 27 & Bayareddypally & 111 & 559 & 5.04 \\
\hline 3 & Oormadigapalle & 15 & 40 & 2.67 & 28 & Somarajukunta & 215 & 800 & 3.72 \\
\hline 4 & Maramkindlapalle & 60 & 96.1 & 1.60 & 29 & $\begin{array}{r}\text { Pedaballi } \\
\text { Harijanawada }\end{array}$ & 24 & 800 & 33.33 \\
\hline 5 & Malmotakapalle & 20 & 92.25 & 4.61 & 30 & Papannagaripalle & 15 & 120 & 8.00 \\
\hline 6 & MKothuru & 77 & 10 & 0.13 & 31 & Nagamvaripalle & 35 & 800 & 22.86 \\
\hline 7 & Holalli & 153 & 240 & 1.57 & 32 & Mundlavaripalle & 100 & 98 & 0.98 \\
\hline 8 & Guddanpura & 49 & 8 & 0.16 & 33 & Dhaiyancheruvu & 300 & 300 & 1.00 \\
\hline 9 & Donakonda & 69 & 97.35 & 1.41 & 34 & Jovukula & 180 & 140 & 0.78 \\
\hline 10 & Sajjupalle & 175 & 743.1 & 4.25 & 35 & Kotireddygaripalle & 25 & 40 & 1.60 \\
\hline 11 & Kundalkurki & 426 & 274.56 & 0.64 & 36 & Byrapalle & 57 & 19.32 & 0.34 \\
\hline 12 & Vemgal & 75 & 42.5 & 0.57 & 37 & E Bairaganahalle & 856 & 4 & 0.00 \\
\hline 13 & Thimmampalle & 120 & 104 & 0.87 & 38 & P Bairaganahalle & 120 & 40 & 0.33 \\
\hline 14 & Yeddulavarikota & 80 & 40 & 0.50 & 39 & Srirampura & 64 & 119.3 & 1.86 \\
\hline 15 & Penderivaripalle & 50 & 25 & 0.50 & 40 & Gudipalle & 109 & 19.32 & 0.18 \\
\hline
\end{tabular}




\begin{tabular}{|c|c|c|c|c|c|c|c|c|c|}
\hline 16 & Kotakadapalle & 110 & 60 & 0.55 & 41 & Gorthapalle Colony & 77 & 60 & 0.78 \\
\hline 17 & Nayanappagaripalle & 60 & 64 & 1.07 & 42 & Saragundlapalle & 60 & 200 & 3.33 \\
\hline 18 & $\begin{array}{r}\text { GuttakindapalleTha } \\
\text { nda }\end{array}$ & 75 & 60 & 0.80 & 43 & Nakkalahalle & 102 & 234.32 & 2.30 \\
\hline 19 & Guddlavaripalle & 20 & 40 & 2.00 & 44 & P.Kothapalle & 35 & 95.75 & 2.74 \\
\hline 20 & Bathanagaaripalle & 85 & 40 & 0.47 & 45 & M.Vyapalapalle & 189 & 654.2 & 3.46 \\
\hline 21 & Chennappagaripalle & 35 & 40 & 1.14 & 46 & Vepulapalli & 43 & 343.8 & 8.00 \\
\hline 22 & Kondappagarihalle & 55 & 248 & 4.51 & 47 & Dandevaripalli & 134 & 78 & 0.58 \\
\hline 23 & $\begin{array}{r}\text { Sunnappukunta } \\
\text { Thanda }\end{array}$ & 69 & 40 & 0.58 & 48 & VK Halli & 213 & 45 & 0.21 \\
\hline 24 & Singannavaripalle & 52 & 950 & 18.27 & 49 & Lakkenahalli & 20 & 194 & 9.70 \\
\hline 25 & RamapuramThanda & 29 & 40 & 1.38 & 50 & $\begin{array}{r}\text { Bathinigaripalli } \\
\text { Tanda }\end{array}$ & 67 & 967 & 14.43 \\
\hline
\end{tabular}

Table A1.2. Success score: biophysical and social outcomes. Using biophysical and social outcomes, we calculated success score to assess overall success in self-governance. To calculate success score, we used a weighted average that considers the same degree of importance of biophysical and social outcomes (the full score of biophysical outcomes $=0.5$; the full score of social outcomes $=0.5$ ). Biophysical outcomes consist of two components (i.e., Resource and Physical Infrastructure). We assigned a score of 0.25 to each of the two biophysical components if it is indicated as "good" $(=1)$; otherwise, a score of 0.00 was assigned to the component. Social outcomes consist of four components (i.e., Human Infrastructure, Trust, Rule Conformance, and Equity). We assigned a score of 0.125 to each of the four social components if it is indicated as "good" $(=1)$; otherwise, a score of 0.00 was assigned to the component. The following formula represents these steps we took to calculate success score:

- $f(i)=1$, if $i=$ "good"; $f(i)=0$, if $i=$ "bad", where $i=$ state of each outcome and $i=$ "good" or "bad"

- Biophysical score $=0.25 \times \sum \quad f(j)$, where $j=$ state of Resource and Physical Infrastructure 
- Social score $=0.125 \times \sum \quad f(k)$, where $k=$ state of Human infrastructure, Trust, Rule Conformance, and Equity

- Total score $=$ Biophysical score + Social score

\begin{tabular}{|c|c|c|c|c|c|c|c|c|c|}
\hline \multirow{2}{*}{$\begin{array}{l}\text { Case } \\
\text { ID }\end{array}$} & \multicolumn{3}{|c|}{ Biophysical Outcomes } & \multicolumn{5}{|c|}{ Social Outcomes } & \multirow{2}{*}{$\begin{array}{c}\text { SUCCESS } \\
\text { SCORE }\end{array}$} \\
\hline & $\begin{array}{l}\text { Resour } \\
\text { ce }\end{array}$ & $\begin{array}{c}\text { Physical } \\
\text { Infrastructure }\end{array}$ & $\begin{array}{c}\text { Biophysical } \\
\text { Score }\end{array}$ & $\begin{array}{c}\text { Human } \\
\text { Infrastructure }\end{array}$ & $\begin{array}{c}\text { Trus } \\
\mathrm{t}\end{array}$ & $\begin{array}{c}\text { Rule } \\
\text { Conformance }\end{array}$ & Equity & Social Score & \\
\hline 1 & 0 & 1 & 0.25 & 1 & 1 & 1 & 1 & 0.50 & 0.75 \\
\hline 2 & 1 & 1 & 0.50 & 1 & 1 & 1 & 1 & 0.50 & 1.00 \\
\hline 3 & 0 & 1 & 0.25 & 1 & 1 & 1 & 1 & 0.50 & 0.75 \\
\hline 4 & 0 & 0 & 0.00 & 1 & 0 & 0 & 1 & 0.25 & 0.25 \\
\hline 5 & 1 & 1 & 0.50 & 1 & 1 & 1 & 1 & 0.50 & 1.00 \\
\hline 6 & 1 & 1 & 0.50 & 1 & 1 & 1 & 1 & 0.50 & 1.00 \\
\hline 7 & 1 & 1 & 0.50 & 1 & 0 & 1 & 1 & 0.375 & 0.875 \\
\hline 8 & 1 & 0 & 0.25 & 1 & 0 & 0 & 0 & 0.125 & 0.375 \\
\hline 9 & 1 & 1 & 0.50 & 1 & 0 & 0 & 0 & 0.125 & 0.625 \\
\hline 10 & 1 & 1 & 0.50 & 1 & 1 & 0 & 0 & 0.25 & 0.75 \\
\hline 11 & 1 & 1 & 0.50 & 1 & 1 & 0 & 0 & 0.25 & 0.75 \\
\hline 12 & 1 & 1 & 0.50 & 1 & 0 & 1 & 1 & 0.375 & 0.875 \\
\hline 13 & 1 & 1 & 0.50 & 1 & 0 & 0 & 0 & 0.125 & 0.625 \\
\hline 14 & 0 & 0 & 0.00 & 1 & 1 & 1 & 1 & 0.50 & 0.50 \\
\hline
\end{tabular}




\begin{tabular}{|c|c|c|c|c|c|c|c|c|c|}
\hline 15 & 1 & 1 & $\mathbf{0 . 5 0}$ & 1 & 1 & 0 & 0 & 0.25 & 0.75 \\
\hline 16 & 1 & 1 & $\mathbf{0 . 5 0}$ & 1 & 1 & 1 & 1 & 0.50 & 1.00 \\
\hline 17 & 1 & 1 & $\mathbf{0 . 5 0}$ & 1 & 0 & 0 & 1 & 0.25 & 0.75 \\
\hline 18 & 1 & 1 & $\mathbf{0 . 5 0}$ & 1 & 1 & 1 & 1 & 0.50 & 1.00 \\
\hline 19 & 1 & 1 & $\mathbf{0 . 5 0}$ & 1 & 0 & 0 & 1 & 0.25 & 0.75 \\
\hline 20 & 0 & 0 & $\mathbf{0 . 0 0}$ & 1 & 1 & 1 & 0 & 0.375 & 0.375 \\
\hline 21 & 1 & 1 & $\mathbf{0 . 5 0}$ & 1 & 1 & 1 & 1 & 0.50 & 1.00 \\
\hline 22 & 1 & 1 & $\mathbf{0 . 5 0}$ & 1 & 1 & 1 & 1 & $\mathbf{0 . 5 0}$ & 1.00 \\
\hline 23 & 0 & 1 & 0.25 & 1 & 0 & 1 & 1 & 0.375 & 0.625 \\
\hline 24 & 0 & 1 & 0.25 & 1 & 0 & 0 & 0 & 0.125 & 0.375 \\
\hline 25 & 1 & 1 & $\mathbf{0 . 5 0}$ & 1 & 1 & 1 & 1 & $\mathbf{0 . 5 0}$ & 1.00 \\
\hline 26 & 1 & 1 & $\mathbf{0 . 5 0}$ & 0 & 0 & 0 & 0 & $\mathbf{0 . 0 0}$ & $\mathbf{0 . 5 0}$ \\
\hline 27 & 0 & 1 & 0.25 & 1 & 0 & 1 & 0 & 0.25 & 0.50 \\
\hline 28 & 1 & 1 & 0.50 & 1 & 0 & 1 & 1 & 0.375 & 0.875 \\
\hline 29 & 0 & 1 & 0.25 & 1 & 1 & 1 & 1 & 0.50 & 0.75 \\
\hline 30 & 1 & 1 & 0.50 & 1 & 1 & 1 & 0 & 0.375 & 0.875 \\
\hline 31 & 1 & 1 & 0.50 & 0 & 0 & 0 & 1 & 0.125 & 0.625 \\
\hline 32 & 0 & 1 & 0.25 & 0 & 0 & 1 & 1 & 0.25 & 0.50 \\
\hline
\end{tabular}




\begin{tabular}{|c|c|c|c|c|c|c|c|c|c|}
\hline 33 & 1 & 1 & $\mathbf{0 . 5 0}$ & 0 & 0 & 1 & 1 & 0.25 & 0.75 \\
\hline 34 & 0 & 1 & 0.25 & 1 & 0 & 0 & 1 & 0.25 & 0.50 \\
\hline 35 & 0 & 1 & 0.25 & 1 & 0 & 1 & 1 & 0.375 & 0.625 \\
\hline 36 & 0 & 0 & 0.00 & 1 & 0 & 0 & 0 & 0.125 & 0.125 \\
\hline 37 & 1 & 1 & $\mathbf{0 . 5 0}$ & 1 & 0 & 0 & 1 & 0.25 & 0.75 \\
\hline 38 & 1 & 1 & $\mathbf{0 . 5 0}$ & 1 & 0 & 1 & 1 & 0.375 & 0.875 \\
\hline 39 & 1 & 1 & $\mathbf{0 . 5 0}$ & 1 & 0 & 1 & 0 & 0.25 & 0.75 \\
\hline 40 & 1 & 0 & 0.25 & 1 & 0 & 0 & 0 & 0.125 & 0.375 \\
\hline 41 & 1 & 1 & $\mathbf{0 . 5 0}$ & 1 & 0 & 0 & 0 & 0.125 & 0.625 \\
\hline 42 & 0 & 1 & 0.25 & 1 & 0 & 1 & 1 & 0.375 & 0.625 \\
\hline 43 & 1 & 1 & $\mathbf{0 . 5 0}$ & 1 & 1 & 1 & 1 & $\mathbf{0 . 5 0}$ & 1.00 \\
\hline 44 & 1 & 1 & $\mathbf{0 . 5 0}$ & 1 & 1 & 1 & 1 & $\mathbf{0 . 5 0}$ & 1.00 \\
\hline 45 & 0 & 1 & 0.25 & 1 & 1 & 1 & 1 & 0.50 & 0.75 \\
\hline 46 & 1 & 1 & $\mathbf{0 . 5 0}$ & 1 & 1 & 1 & 1 & 0.50 & 1.00 \\
\hline 47 & 1 & 1 & 0.50 & 1 & 1 & 1 & 1 & 0.50 & 1.00 \\
\hline 48 & 0 & 1 & 0.25 & 1 & 1 & 1 & 1 & 0.50 & 0.75 \\
\hline 49 & 1 & 0 & 0.25 & 1 & 0 & 0 & 1 & 0.25 & $\mathbf{0 . 5 0}$ \\
\hline 50 & 0 & 1 & 0.25 & 0 & 0 & 1 & 1 & 0.25 & $\mathbf{0 . 5 0}$ \\
\hline
\end{tabular}



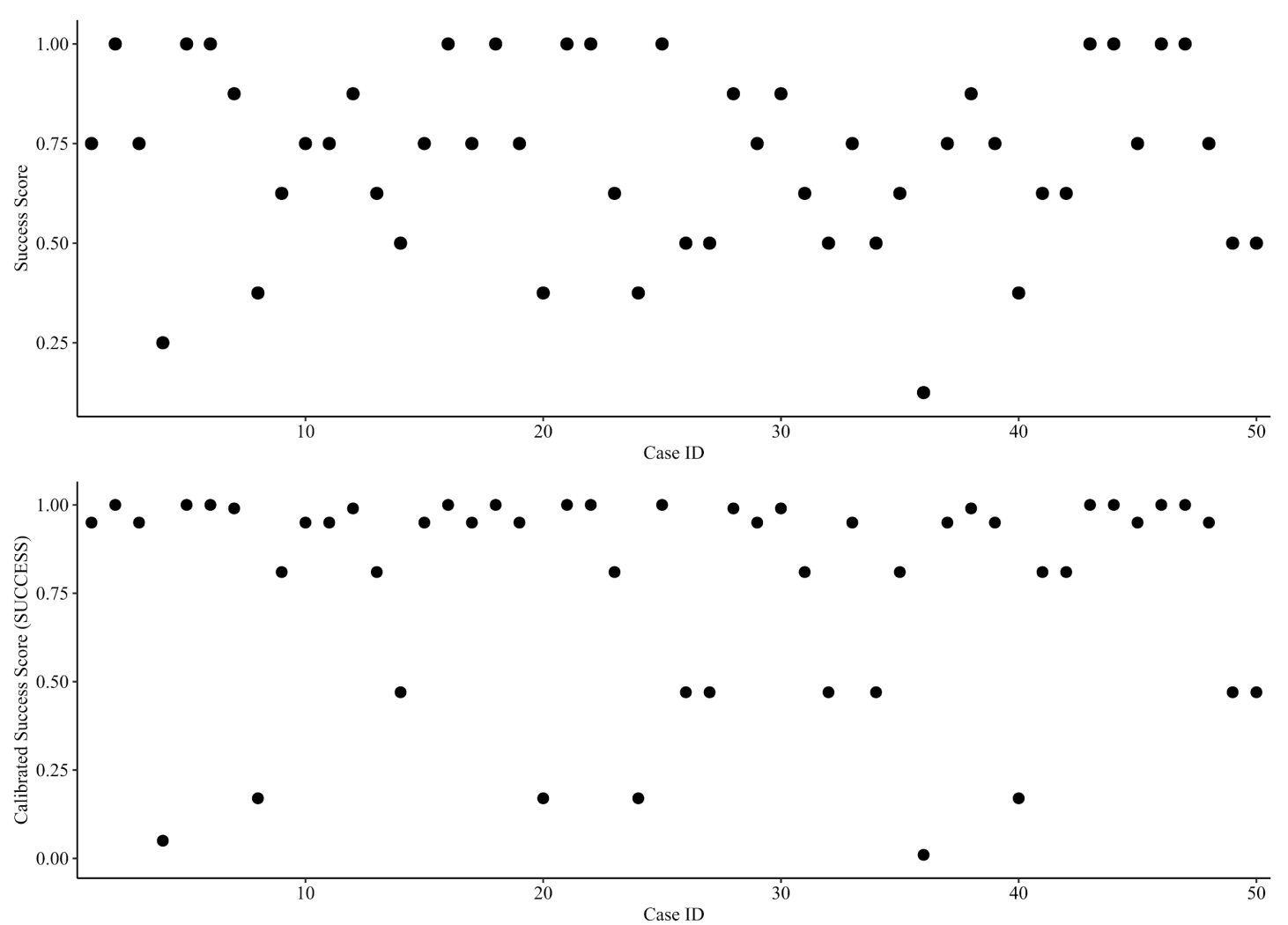

Fig. A1.1. Distribution of success score across villages (top) and distribution of the calibrated success score (SUCCESS) across villages (bottom). The variable success score was calibrated to indicate degree of membership in a set of successful self-governance. To do so, we used a calibration function which is embedded in the fsQCA 3.0 software and named "calibrate (x, n1, n2, n3)". For our study, x was replaced with the success score that we need to calibrate. We input 0.75 into $\mathrm{n} 1,0.51$ into 2 , and 0.25 into $\mathrm{n} 3$. The first value 0.75 is the threshold for full membership in the set of successful self-governance (high success; fuzzy score $=0.95$ ). The second value 0.51 represents the crossover point (medium success; fuzzy score $=0.5$ ). The last value 0.25 corresponds to the threshold for full non-membership in the set of successful selfgovernance (low success; fuzzy score $=0$ ). These three qualitative breakpoints were used to convert the success score into fuzzy membership scores, using transformations based on the log odds of full membership (Ragin and Davey, 2017) 


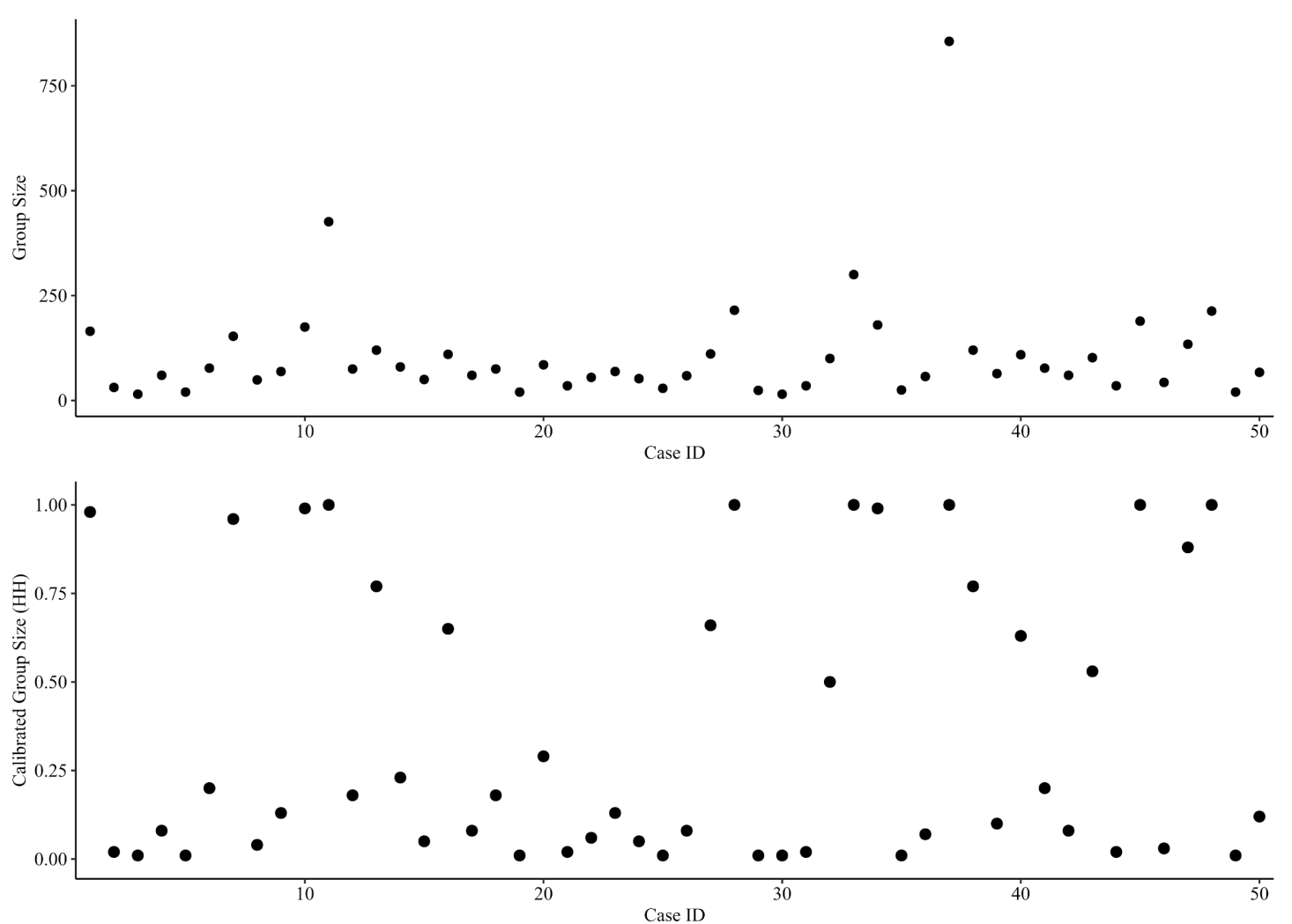

Fig. A1.2. Distribution of \# of households across villages (top) and distribution of the calibrated \# of households (HH) across villages

(bottom). The contextual variable group size was calibrated to indicate degree of membership in a set of large group size. To do so, we used a calibration function which is embedded in the fsQCA 3.0 software and named "calibrate (x, n1, n2, n3)". For our study, x was replaced with group size that we need to calibrate. We input 150 into $\mathrm{n} 1,100$ into $\mathrm{n} 2$, and 50 into $\mathrm{n} 3$. The first value 150 means the threshold for full membership in the set of large group size (fuzzy score $=0.95$ ). The second value 100 represents the crossover point (fuzzy score $=0.5$ ). The last value 50 corresponds to the threshold for full non-membership in the set of large group size (fuzzy score $=0$ ). These three qualitative breakpoints were used to convert the success score into fuzzy membership scores, using transformations based on the log odds of full membership (Ragin and Davey, 2017) 


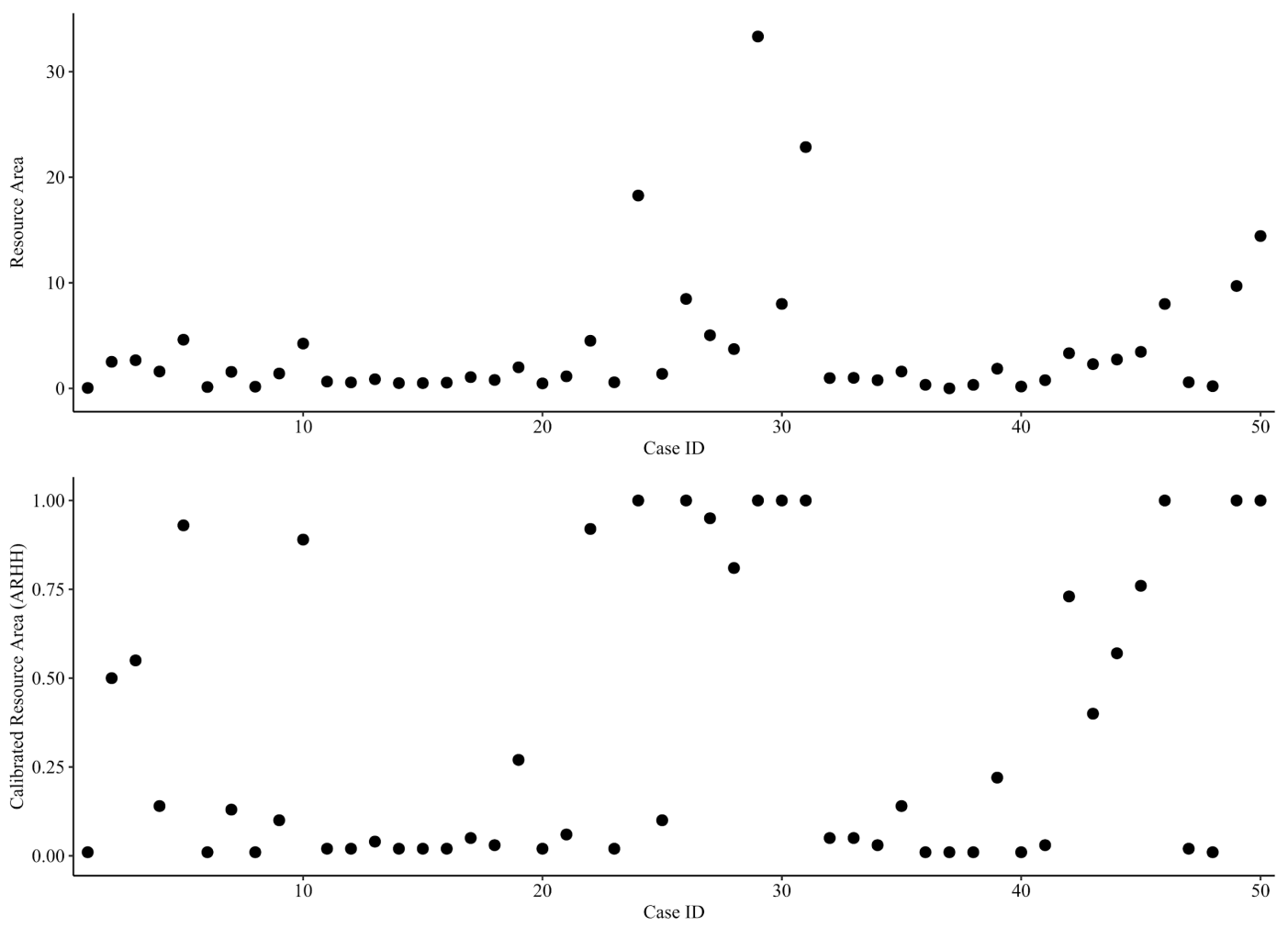

Fig. A1.3. Distribution of resource area across villages (top) and distribution of the calibrated resource area per household (ARHH) across villages (bottom). The contextual variable resource area was calibrated to indicate degree of membership in a set of large resource areas. To do so, we used a calibration function which is embedded in the fsQCA 3.0 software and named "calibrate (x, n1, n2, n3)". For our study, x was replaced with resource area that we need to calibrate. We input 5.0 into n1, 2.5 into n2, and 1.0 into n3. The first value 5.0 means the threshold for full membership in the set of large resource areas (fuzzy score $=0.95$ ). The second value 2.5 represents the cross-over point (fuzzy score $=0.5$ ). The last value 1.0 corresponds to the threshold for full non-membership in the set of large resource areas (fuzzy score $=0$ ). These three qualitative breakpoints were used to convert the success score into fuzzy membership scores, using transformations based on the log odds of full membership (Ragin and Davey, 2017) 
Table A1.3. Fuzzy-set values of all conditions and the outcome. The institutional conditions (DPs) were dichotomously coded by assigning "1" to the presence and " 0 " to the absence. The fuzzy-set values of HH are the results of calibrating \# of households (see Fig. A1.2. for details on how we calibrated it). The fuzzy-set values of ARHH are the results of calibrating resource areas per household (see Fig. A1.3. for details on how we calibrated it). The fuzzy-set values of SUCCESS are the results of calibrating success score (see Fig. A1.1 for details on how we calibrated it).

\begin{tabular}{|c|c|c|c|c|c|c|c|c|c|c|c|c|c|c|}
\hline $\begin{array}{c}\text { Case } \\
\#\end{array}$ & $\mathrm{HH}$ & ARHH & DP1A & DP1B & DP2A & DP2B & DP3 & $\mathrm{DP} 4 \mathrm{~A}$ & DP4B & DP5 & DP6 & DP7 & DP8 & SUCCESS \\
\hline 1 & 0.98 & 0.01 & 1 & 1 & 0 & 0 & 0 & 0 & 0 & 0 & 1 & 1 & 0 & 0.95 \\
\hline 2 & 0.02 & 0.50 & 1 & 1 & 1 & 1 & 1 & 1 & 0 & 0 & 1 & 1 & 1 & 1.00 \\
\hline 3 & 0.01 & 0.55 & 0 & 0 & 1 & 1 & 0 & 0 & 0 & 0 & 1 & 0 & 1 & 0.95 \\
\hline 4 & 0.08 & 0.14 & 1 & 0 & 1 & 1 & 0 & 0 & 0 & 0 & 1 & 1 & 1 & 0.05 \\
\hline 5 & 0.01 & 0.93 & 1 & 1 & 1 & 1 & 1 & 1 & 1 & 1 & 1 & 1 & 1 & 1.00 \\
\hline 6 & 0.20 & 0.01 & 1 & 1 & 0 & 0 & 1 & 1 & 1 & 0 & 1 & 1 & 1 & 1.00 \\
\hline 7 & 0.96 & 0.13 & 1 & 0 & 1 & 0 & 0 & 0 & 0 & 0 & 1 & 1 & 1 & 0.99 \\
\hline 8 & 0.04 & 0.01 & 1 & 0 & 0 & 0 & 0 & 0 & 0 & 0 & 1 & 1 & 1 & 0.17 \\
\hline 9 & 0.13 & 0.10 & 1 & 1 & 1 & 1 & 1 & 1 & 0 & 0 & 1 & 1 & 1 & 0.81 \\
\hline 10 & 0.99 & 0.89 & 1 & 1 & 1 & 1 & 1 & 1 & 0 & 1 & 1 & 1 & 1 & 0.95 \\
\hline 11 & 1.00 & 0.02 & 1 & 0 & 0 & 0 & 0 & 0 & 0 & 0 & 0 & 0 & 1 & 0.95 \\
\hline 12 & 0.18 & 0.02 & 1 & 1 & 1 & 1 & 1 & 1 & 0 & 1 & 1 & 1 & 1 & 0.99 \\
\hline 13 & 0.77 & 0.04 & 1 & 1 & 1 & 1 & 1 & 1 & 0 & 1 & 1 & 1 & 1 & 0.81 \\
\hline 14 & 0.23 & 0.02 & 1 & 1 & 1 & 1 & 1 & 1 & 0 & 1 & 1 & 1 & 1 & 0.47 \\
\hline 15 & 0.05 & 0.02 & 1 & 1 & 1 & 1 & 1 & 1 & 0 & 1 & 1 & 0 & 1 & 0.95 \\
\hline
\end{tabular}




\begin{tabular}{|c|c|c|c|c|c|c|c|c|c|c|c|c|c|c|}
\hline 16 & 0.65 & 0.02 & 1 & 1 & 1 & 1 & 1 & 1 & 0 & 1 & 1 & 0 & 1 & 1.00 \\
\hline 17 & 0.08 & 0.05 & 1 & 1 & 1 & 1 & 1 & 1 & 0 & 1 & 1 & 1 & 1 & 0.95 \\
\hline 18 & 0.18 & 0.03 & 1 & 1 & 1 & 1 & 1 & 1 & 1 & 1 & 1 & 1 & 1 & 1.00 \\
\hline 19 & 0.01 & 0.27 & 1 & 1 & 1 & 1 & 1 & 1 & 0 & 1 & 1 & 1 & 1 & 0.95 \\
\hline 20 & 0.29 & 0.02 & 1 & 1 & 1 & 1 & 1 & 1 & 0 & 1 & 1 & 1 & 1 & 0.17 \\
\hline 21 & 0.02 & 0.06 & 1 & 1 & 1 & 1 & 1 & 1 & 0 & 1 & 1 & 1 & 1 & 1.00 \\
\hline 22 & 0.06 & 0.92 & 1 & 0 & 1 & 0 & 0 & 0 & 0 & 0 & 1 & 1 & 1 & 1.00 \\
\hline 23 & 0.13 & 0.02 & 1 & 1 & 1 & 0 & 0 & 0 & 0 & 0 & 0 & 1 & 1 & 0.81 \\
\hline 24 & 0.05 & 1.00 & 1 & 0 & 1 & 1 & 0 & 0 & 0 & 0 & 1 & 1 & 0 & 0.17 \\
\hline 25 & 0.01 & 0.10 & 1 & 0 & 0 & 0 & 1 & 0 & 0 & 0 & 1 & 1 & 1 & 1.00 \\
\hline 26 & 0.08 & 1.00 & 1 & 0 & 1 & 1 & 1 & 0 & 0 & 0 & 1 & 1 & 1 & 0.47 \\
\hline 27 & 0.66 & 0.95 & 1 & 1 & 1 & 1 & 1 & 1 & 0 & 1 & 1 & 1 & 1 & 0.47 \\
\hline 28 & 1.00 & 0.81 & 1 & 1 & 1 & 1 & 0 & 1 & 0 & 1 & 1 & 0 & 1 & 0.99 \\
\hline 29 & 0.01 & 1.00 & 0 & 0 & 0 & 0 & 0 & 0 & 0 & 0 & 0 & 1 & 0 & 0.95 \\
\hline 30 & 0.01 & 1.00 & 1 & 1 & 0 & 0 & 1 & 0 & 0 & 0 & 0 & 1 & 0 & 0.99 \\
\hline 31 & 0.02 & 1.00 & 1 & 1 & 1 & 1 & 1 & 1 & 0 & 1 & 1 & 0 & 1 & 0.81 \\
\hline 32 & 0.50 & 0.05 & 1 & 1 & 1 & 1 & 1 & 1 & 0 & 0 & 1 & 1 & 1 & 0.47 \\
\hline 33 & 1.00 & 0.05 & 1 & 1 & 1 & 1 & 1 & 1 & 0 & 1 & 1 & 1 & 1 & 0.95 \\
\hline 34 & 0.99 & 0.03 & 1 & 0 & 0 & 0 & 1 & 1 & 0 & 1 & 1 & 0 & 1 & 0.47 \\
\hline 35 & 0.01 & 0.14 & 1 & 1 & 1 & 1 & 1 & 1 & 0 & 1 & 1 & 1 & 1 & 0.81 \\
\hline
\end{tabular}




\begin{tabular}{|c|c|c|c|c|c|c|c|c|c|c|c|c|c|c|}
\hline 36 & 0.07 & 0.01 & 1 & 0 & 1 & 1 & 1 & 1 & 0 & 0 & 1 & 0 & 1 & 0.01 \\
\hline 37 & 1.00 & 0.01 & 1 & 1 & 1 & 1 & 1 & 1 & 0 & 0 & 0 & 0 & 1 & 0.95 \\
\hline 38 & 0.77 & 0.01 & 1 & 1 & 1 & 1 & 1 & 0 & 0 & 0 & 1 & 0 & 1 & 0.99 \\
\hline 39 & 0.10 & 0.22 & 1 & 0 & 1 & 1 & 0 & 0 & 0 & 0 & 1 & 1 & 1 & 0.95 \\
\hline 40 & 0.63 & 0.01 & 1 & 0 & 1 & 1 & 1 & 0 & 0 & 0 & 1 & 1 & 1 & 0.17 \\
\hline 41 & 0.20 & 0.03 & 1 & 1 & 1 & 1 & 1 & 1 & 0 & 1 & 1 & 1 & 1 & 0.81 \\
\hline 42 & 0.08 & 0.73 & 1 & 1 & 1 & 1 & 1 & 1 & 0 & 0 & 1 & 1 & 1 & 0.81 \\
\hline 43 & 0.53 & 0.40 & 1 & 1 & 1 & 1 & 1 & 1 & 0 & 1 & 1 & 1 & 1 & 1 \\
\hline 44 & 0.02 & 0.57 & 1 & 1 & 0 & 1 & 1 & 0 & 0 & 1 & 1 & 1 & 0 & 1 \\
\hline 45 & 1.00 & 0.76 & 1 & 1 & 1 & 1 & 1 & 1 & 0 & 1 & 1 & 1 & 0 & 0.95 \\
\hline 46 & 0.03 & 1.00 & 0 & 1 & 0 & 1 & 1 & 1 & 0 & 1 & 1 & 1 & 1 & 1 \\
\hline 47 & 0.88 & 0.02 & 1 & 1 & 0 & 1 & 1 & 0 & 0 & 0 & 1 & 1 & 0 & 1 \\
\hline 48 & 1.00 & 0.01 & 1 & 1 & 0 & 0 & 1 & 1 & 0 & 1 & 1 & 1 & 0 & 0.95 \\
\hline 49 & 0.01 & 1.00 & 0 & 0 & 0 & 0 & 0 & 0 & 0 & 0 & 1 & 1 & 1 & 0.47 \\
\hline 50 & 0.12 & 1.00 & 1 & 1 & 0 & 0 & 1 & 0 & 0 & 1 & 1 & 1 & 0 & 0.47 \\
\hline
\end{tabular}


Table A1.4. Truth Tables for the analysis of sufficiency for successful self-governance. This table was generated by the fsQCA 3.0 software (Ragin and Davey, 2016). The frequency threshold should be 1 or 2 when the total number of cases is relatively small (Ragin and Davey, 2017).

The recommended value of the consistency threshold is between 0.8 and 0.9 based on QCA best practices (Basurto, 2013). The frequency

threshold of 2 was chosen, and the consistency threshold of 0.8 was selected.

Model 1: SUCCESS = f(DP1A, DP1B, DP2A, DP2B, DP3, DP4A, DP5, DP6, DP7, DP8)

\begin{tabular}{|c|c|c|c|c|c|c|c|c|c|c|c|c|}
\hline \multirow[t]{6}{*}{$\begin{array}{l}\text { No contextual } \\
\text { conditions }\end{array}$} & $\begin{array}{c}\text { DP1 } \\
\text { A }\end{array}$ & $\begin{array}{c}\mathrm{DP} 1 \\
\mathrm{~B}\end{array}$ & $\begin{array}{c}\mathrm{DP} 2 \\
\mathrm{~A}\end{array}$ & $\begin{array}{c}\mathrm{DP} 2 \\
\mathrm{~B}\end{array}$ & $\begin{array}{c}\text { DP } \\
3\end{array}$ & $\begin{array}{c}\mathrm{DP} 4 \\
\mathrm{~A}\end{array}$ & $\begin{array}{c}\text { DP } \\
5\end{array}$ & DP6 & DP7 & DP8 & $\begin{array}{l}\text { SUCCE } \\
\text { SS }\end{array}$ & N (Case \#) \\
\hline & 1 & 1 & 1 & 1 & 1 & 1 & 1 & 1 & 0 & 1 & 1 & $3(151631)$ \\
\hline & 1 & 1 & 1 & 1 & 1 & 1 & 1 & 1 & 1 & 1 & 1 & 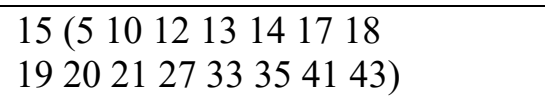 \\
\hline & 1 & 1 & 1 & 1 & 1 & 1 & 0 & 1 & 1 & 1 & 0 & $4(293242)$ \\
\hline & 1 & 0 & 1 & 1 & 0 & 0 & 0 & 1 & 1 & 1 & 0 & $2(4$ 39) \\
\hline & 1 & 0 & 1 & 1 & 1 & 0 & 0 & 1 & 1 & 1 & 0 & $2(2640)$ \\
\hline \multicolumn{13}{|c|}{ Model 2: SUCCESS = f(HH, DP1A, DP1B, DP2A, DP2B, DP3, DP4A, DP5, DP6, DP7, DP8) } \\
\hline $\mathrm{HH}$ & $\begin{array}{c}\mathrm{DP} 1 \\
\mathrm{~A}\end{array}$ & $\begin{array}{c}\text { DP1 } \\
\text { B }\end{array}$ & $\begin{array}{c}\mathrm{DP} 2 \\
\mathrm{~A}\end{array}$ & $\begin{array}{c}\mathrm{DP} 2 \\
\mathrm{~B}\end{array}$ & $\begin{array}{c}\mathrm{DP} \\
3\end{array}$ & $\begin{array}{c}\mathrm{DP} 4 \\
\mathrm{~A}\end{array}$ & $\begin{array}{c}\mathrm{DP} \\
5\end{array}$ & DP6 & DP7 & DP8 & \begin{tabular}{|l} 
SUCCE \\
SS
\end{tabular} & N (Case \#) \\
\hline 0 & 1 & 1 & 1 & 1 & 1 & 1 & 0 & 1 & 1 & 1 & 1 & $3(2942)$ \\
\hline 0 & 1 & 1 & 1 & 1 & 1 & 1 & 1 & 1 & 0 & 1 & 1 & $2(1531)$ \\
\hline 1 & 1 & 1 & 1 & 1 & 1 & 1 & 1 & 1 & 1 & 1 & 1 & $5(1013273343)$ \\
\hline 0 & 1 & 1 & 1 & 1 & 1 & 1 & 1 & 1 & 1 & 1 & 1 & $10(5121417181920213541)$ \\
\hline 0 & 1 & 0 & 1 & 1 & 0 & 0 & 0 & 1 & 1 & 1 & 0 & $2(439)$ \\
\hline
\end{tabular}




\begin{tabular}{|c|c|c|c|c|c|c|c|c|c|c|c|c|}
\hline ARHH & $\begin{array}{c}\mathrm{DP} 1 \\
\mathrm{~A}\end{array}$ & $\begin{array}{c}\mathrm{DP} 1 \\
\mathrm{~B}\end{array}$ & $\begin{array}{c}\mathrm{DP} 2 \\
\mathrm{~A}\end{array}$ & $\begin{array}{c}\mathrm{DP} 2 \\
\mathrm{~B}\end{array}$ & $\begin{array}{c}\mathrm{DP} \\
3\end{array}$ & $\begin{array}{c}\mathrm{DP} 4 \\
\mathrm{~A}\end{array}$ & $\begin{array}{c}\mathrm{DP} \\
5\end{array}$ & DP6 & DP7 & DP8 & $\begin{array}{l}\text { SUCCE } \\
\text { SS }\end{array}$ & N (Case \#) \\
\hline 0 & 1 & 1 & 1 & 1 & 1 & 1 & 1 & 1 & 0 & 1 & 1 & $2(1516)$ \\
\hline 1 & 1 & 1 & 1 & 1 & 1 & 1 & 1 & 1 & 1 & 1 & 1 & $3\left(\begin{array}{lll}5 & 10 & 27\end{array}\right)$ \\
\hline 0 & 1 & 1 & 1 & 1 & 1 & 1 & 1 & 1 & 1 & 1 & 1 & $\begin{array}{l}12(12131417181920213335 \\
4143)\end{array}$ \\
\hline 0 & 1 & 1 & 1 & 1 & 1 & 1 & 0 & 1 & 1 & 1 & 0 & $2\left(\begin{array}{ll}9 & 32\end{array}\right)$ \\
\hline 0 & 1 & 0 & 1 & 1 & 0 & 0 & 0 & 1 & 1 & 1 & 0 & $2(439)$ \\
\hline
\end{tabular}

Table A1.5. Cases with greater than or equal to 0.75 membership in each solution term

Outcome: successful self-governance

\begin{tabular}{|c|c|c|}
\hline & Combinations of conditions (Intermediate solution) & $\begin{array}{l}\text { Cases with greater than or equal to } 0.75 \text { membership in a solution } \\
\text { term }\end{array}$ \\
\hline Model 1 & $\begin{array}{l}\text { (C1) } \\
\text { DP1A*DP1B*DP2A*DP2B*DP3*DP4A*DP5*DP6*DP8 }\end{array}$ & $\begin{array}{l}5(1,1), 10(1,0.95), 12(1,0.99), 13(1,0.81), 14(1,0.47), \\
15(1,0.95), 16(1,1), 17(1,0.95), 18(1,1), 19(1,0.95), \\
20(1,0.17), 21(1,1), 27(1,0.47), 31(1,0.81), 33(1,0.95), \\
35(1,0.81), 41(1,0.81), 43(1,1)\end{array}$ \\
\hline Model 2 & $\begin{array}{l}(\mathrm{C} 2) \\
\text { hh*DP1A*DP1B*DP2A*DP2B*DP3*DP4A*DP5*DP6*DP } \\
8+ \\
(\mathrm{C} 3) \\
\text { hh*DP1A*DP1B*DP2A*DP2B*DP3*DP4A*DP6*DP7*DP } \\
8+\end{array}$ & $\begin{array}{l}5(0.99,1), 19(0.99,0.95), 35(0.99,0.81), 21(0.98,1), 31(0.98,0.81), \\
15(0.95,0.95), 17(0.92,0.95), 12(0.82,0.99), 18(0.82,1), 41 \\
(0.8,0.81), \\
14(0.77,0.47), 20(0.71,0.17) \\
\\
5(0.99,1), 19(0.99,0.95), 35(0.99,0.81), 2(0.98,1), 21(0.98,1), \\
17(0.92,0.95), 42(0.92,0.81), 9(0.87,0.81), 12(0.82,0.99), 18 \\
(0.82,1), \\
41(0.8,0.81), 14(0.77,0.47), 20(0.71,0.17)\end{array}$ \\
\hline
\end{tabular}




\begin{tabular}{|c|c|c|}
\hline & $\begin{array}{l}(\mathrm{C} 4) \\
\mathrm{DP} 1 \mathrm{~A} * \mathrm{DP} 1 \mathrm{~B} * \mathrm{DP} 2 \mathrm{~A} * \mathrm{DP} 2 \mathrm{~B} * \mathrm{DP} 3 * \mathrm{DP} 4 \mathrm{~A} * \mathrm{DP} 5 * \mathrm{DP} 6 * \mathrm{DP} 7 * \mathrm{D} \\
\text { P8 }\end{array}$ & $\begin{array}{l}5(1,1), 10(1,0.95), 12(1,0.99), 13(1,0.81), 14(1,0.47), \\
17(1,0.95), 18(1,1), 19(1,0.95), 20(1,0.17), 21(1,1), \\
27(1,0.47), 33(1,0.95), 35(1,0.81), 41(1,0.81), 43(1,1)\end{array}$ \\
\hline Model 3 & $\begin{array}{l}(\mathrm{C} 5) \\
\operatorname{arhh} * \mathrm{DP} 1 \mathrm{~A} * \mathrm{DP} 1 \mathrm{~B} * \mathrm{DP} 2 \mathrm{~A} * \mathrm{DP} 2 \mathrm{~B} * \mathrm{DP} 3 * \mathrm{DP} 4 \mathrm{~A} * \mathrm{DP} 5 * \mathrm{DP} 6 * \\
\mathrm{DP} 8+ \\
(\mathrm{C} 6) \\
\mathrm{DP} 1 \mathrm{~A} * \mathrm{DP} 1 \mathrm{~B} * \mathrm{DP} 2 \mathrm{~A} * \mathrm{DP} 2 \mathrm{~B} * \mathrm{DP} 3 * \mathrm{DP} 4 \mathrm{~A} * \mathrm{DP} 5 * \mathrm{DP} 6 * \mathrm{DP} 7 * \mathrm{D} \\
\mathrm{P} 8\end{array}$ & $\begin{array}{l}12(0.98,0.99), 14(0.98,0.47), 15(0.98,0.95), 16(0.98,1), 20 \\
(0.98,0.17), \\
18(0.97,1), 41(0.97,0.81), 13(0.96,0.81), 17(0.95,0.95), 33 \\
(0.95,0.95), \\
21(0.94,1), 35(0.86,0.81), 19(0.73,0.95), 43(0.6,1) \\
5(1,1), 10(1,0.95), 12(1,0.99), 13(1,0.81), 14(1,0.47), \\
17(1,0.95), 18(1,1), 19(1,0.95), 20(1,0.17), 21(1,1), \\
27(1,0.47), 33(1,0.95), 35(1,0.81), 41(1,0.81), 43(1,1)\end{array}$ \\
\hline
\end{tabular}

- Acronyms: DP (presence of Design Principle); HH (large group size); ARHH (large resource area per household)

- Lowercase characters represent weak membership in the set of villages with large group size (hh) and with large resource area per household (arhh). Boldface letters emphasize two contextual conditions (group size and resource area).

- The symbol of "+" represents the logical operator OR and the "*" represents AND.

\author{
Model 1: Solution coverage $=0.387$; Solution consistency $=0.838$ \\ Model 2: Solution coverage $=0.449 ;$ Solution consistency $=0.852$ \\ Model 3: Solution coverage $=0.366$; Solution consistency $=0.841$
}

\title{
Table A1.6. Sensitivity analysis
}

This table shows the simplified solution formula ${ }^{\dagger}$ under the assumption that each DP (Design Principle) contributes to successful self-governance when present or absent. The results are the same as those shown in Table 3 where we assumed that each DP contributes to successful selfgovernance when present. 


\begin{tabular}{l} 
Outcome: successful self-governance \\
\hline \\
\hline
\end{tabular}

- Acronyms: DP (presence of Design Principle); HH (large group size); ARHH (large resource area per household)

- Lowercase characters represent weak membership in the set of villages with large group size (hh) and with large resource area per household (arhh). Boldface letters emphasize two contextual conditions (group size and resource area).

- The symbol of "+" represents the logical operator OR and the "*" represents AND.

\footnotetext{
Model 1: Solution coverage $=0.387$; Solution consistency $=0.838$

Model 2: Solution coverage $=0.449$; Solution consistency $=0.852$

Model 3: Solution coverage $=0.366$; Solution consistency $=0.841$

'See Table A1.5 in Appendix 1 for cases with greater than 0.5 membership in each solution term

${ }^{\dagger}$ Raw coverage measures the proportion of memberships in the outcome explained by each solution term. This measure is calculated by dividing the sum of consistent membership in the solution term by the sum of membership in the outcome (Ragin and Davey, 2016)
} 
Table A1.7. Disaggregated model solutions

\begin{tabular}{|c|c|c|c|}
\hline \multicolumn{4}{|c|}{ Outcome: resource outcome } \\
\hline & Combinations of conditions (Intermediate solution) ${ }^{\dagger}$ & $\begin{array}{c}\text { Solution } \\
\text { consistency }\end{array}$ & $\begin{array}{l}\text { Solution } \\
\text { coverage }\end{array}$ \\
\hline Model 1 & $\begin{array}{l}\mathrm{DP} 1 \mathrm{~A} * \mathrm{DP} 2 \mathrm{~A} * \mathrm{DP} 2 \mathrm{~B} * \mathrm{DP} 3 * \sim \mathrm{DP} 4 \mathrm{~A} * \mathrm{DP} 6 * \mathrm{DP} 7 * \mathrm{DP} 8+ \\
\mathrm{DP} 1 \mathrm{~A} * \sim \mathrm{DP} 1 \mathrm{~B} * \mathrm{DP} 2 \mathrm{~A} * \mathrm{DP} 2 \mathrm{~B} * \mathrm{DP} 3 * \mathrm{DP} 6 * \mathrm{DP} 7 * \mathrm{DP} 8+ \\
\mathrm{DP} 1 \mathrm{~A} * \mathrm{DP} 1 \mathrm{~B} * \mathrm{DP} 2 \mathrm{~A} * \mathrm{DP} 2 \mathrm{~B} * \mathrm{DP} 3 * \mathrm{DP} 4 \mathrm{~A} * \mathrm{DP} 5 * \mathrm{DP} 6 * \sim \mathrm{DP} 7 * \mathrm{DP} 8\end{array}$ & 1 & 0.15 \\
\hline Model 2 & $\mathbf{h h} * \mathrm{DP} 1 \mathrm{~A}^{*} \mathrm{DP} 1 \mathrm{~B} * \mathrm{DP} 2 \mathrm{~A} * \mathrm{DP} 2 \mathrm{~B} * \mathrm{DP} 3 * \mathrm{DP} 4 \mathrm{~A} * \mathrm{DP} 5 * \mathrm{DP} 6 * \sim \mathrm{DP} 7 * \mathrm{DP} 8$ & 1 & 0.07 \\
\hline Model 3 & arhh*DP1A*DP1B*DP2A*DP2B*DP3*DP4A*DP5*DP6* DP7*DP8 & 1 & 0.06 \\
\hline \multicolumn{4}{|c|}{ Outcome: physical infrastructure outcome } \\
\hline & Combinations of conditions (Intermediate solution) ${ }^{\dagger}$ & $\begin{array}{c}\text { Solution } \\
\text { consistency }\end{array}$ & $\begin{array}{l}\text { Solution } \\
\text { coverage }\end{array}$ \\
\hline Model 1 & $\begin{array}{l}\mathrm{DP} 1 \mathrm{~A} * \mathrm{DP} 1 \mathrm{~B} * \mathrm{DP} 2 \mathrm{~A} * \mathrm{DP} 2 \mathrm{~B} * \mathrm{DP} 3 * \mathrm{DP} 4 \mathrm{~A} * \mathrm{DP} 5 * \mathrm{DP} 6 * \mathrm{DP} 8+ \\
\mathrm{DP} 1 \mathrm{~A} * \mathrm{DP} 1 \mathrm{~B} * \mathrm{DP} 2 \mathrm{~A} * \mathrm{DP} 2 \mathrm{~B} * \mathrm{DP} 3 * \mathrm{DP} 4 \mathrm{~A} * \mathrm{DP} 6 * \mathrm{DP} 7 * \mathrm{DP} 8\end{array}$ & 0.91 & 0.47 \\
\hline Model 2 & $\mathbf{h h} * \mathrm{DP} 1 \mathrm{~A} * \mathrm{DP} 1 \mathrm{~B} * \mathrm{DP} 2 \mathrm{~A} * \mathrm{DP} 2 \mathrm{~B} * \mathrm{DP} 3 * \mathrm{DP} 4 \mathrm{~A} * \mathrm{DP} 5 * \mathrm{DP} 6 * \mathrm{DP}+$ & 0.90 & 0.43 \\
\hline
\end{tabular}




\begin{tabular}{l|l|c|c}
\hline & $\begin{array}{l}\text { hh*DP1A*DP1B*DP2A*DP2B*DP3*DP4A*DP6*DP7*DP8 } \\
\text { DP1A*DP1B*DP2A*DP2B*DP3*DP4A*DP5*DP6*DP7*DP8 }\end{array}$ & \\
\hline Mode1 3 & $\begin{array}{l}\text { arhh*DP1A*DP1B*DP2A*DP2B*DP3*DP4A*DP5*DP6*DP8 + } \\
\text { arhh*DP1A*DP1B*DP2A*DP2B*DP3*DP4A*DP6*DP7*DP8 + }\end{array}$ & 0.90 & 0.41 \\
\hline DP1A*DP1B*DP2A*DP2B*DP3*DP4A*DP5*DP6*DP7*DP8 & & \\
\hline Outcome: social outcome & & \\
\hline Model 1 & No combinations (or solution) were found ${ }^{\dagger \dagger}$ & & \\
\hline Model 2 & arhh*DP1A*DP1B*DP2A*DP2B*DP3*DP4A*DP5*DP6*DP7*DP8 & 0.80 & N/A \\
\hline Model 3 & No combinations (or solutions) were found & & \\
\hline
\end{tabular}

- Acronyms: DP (presence of Design Principle); HH (large group size); ARHH (large resource area per household) - Lowercase characters represent weak membership in the set of villages with large group size (hh) and with large resource area per household (arhh). Boldface letters emphasize two contextual conditions (group size and resource area).

- The symbol of "+" represents the logical operator OR and the "*" represents AND.

${ }^{\dagger}$ To produce intermediate solutions, we assumed that HH (large group size) and ARHH (large resource area) could contribute to successful self-governance when it is present or absent, and that DPs could contribute to this outcome when they are present.

${ }^{\dagger} T$ The variable social score was calibrated to indicate degree of membership in a set of biophysical successful cases. To do so, we used a calibration function which is embedded in the fsQCA 3.0 software and named "calibrate (x, n1, 
$\mathrm{n} 2, \mathrm{n} 3)$ ". For our study, $\mathrm{x}$ was replaced with the social score that we need to calibrate. We input 0.50 into $\mathrm{n} 1,0.25$ into $\mathrm{n} 2$, and 0.00 into $\mathrm{n} 3$. The first value 0.50 is the threshold for full membership in the set of social success (high success; fuzzy score $=0.95$ ). The second value 0.25 represents the crossover point (medium success; fuzzy score $=0.5$ ). The last value 0.00 corresponds to the threshold for full non-membership in the set of social success (low success;

fuzzy score $=0.05$ ). These three qualitative breakpoints were used to convert the success score into fuzzy membership scores, using transformations based on the log odds of full membership (Ragin and Davey, 2017). The frequency

threshold in QCA models must be 1 or 2 when the total number of cases is relatively small (Ragin and Davey, 2017).

The recommended value of the consistency threshold is between 0.8 and 0.9 based on QCA best practices (Basurto,

2013). For running our models, we set the frequency threshold to 2 and the consistency threshold at 0.8 . No

combinations or solutions were found by fsQCA for this parameter setting for social outcomes. The fsQCA software shows the following error message; "Error (Quine-McCluskey algorithm): The 1 Matrix is Empty." This means that no "success" (coded as 1) cases are found in our sample when the frequency threshold (i.e., threshold \# of cases) is 2.

\section{References}

Basurto, X., 2013. Linking multi-level governance to local common-pool resource theory using fuzzy-set qualitative comparative analysis: insights from twenty years of biodiversity conservation in Costa Rica. Glob. Environ. Chang. 23, 573-587.

https://doi.org/10.1016/j.gloenvcha.2013.02.011

Ragin, C.C., Davey, S., 2017. User's Guide to Fuzzy-Set/Qualitative Comparative Analysis. Irvine, California: Department of Sociology, University of California.

Ragin, C.C., Davey, S., 2016. Fuzzy-Set/Qualitative Comparative Analysis 3.0. Irvine, California: Department of Sociology, University of California. 